\title{
A INFLUÊNCIA DO BOARD INTERLOCKING NA QUALIDADE DA INFORMAÇÃO CONTÁBIL EM EMPRESAS BRASILEIRAS
}

\section{THE INFLUENCE OF BOARD INTERLOCKING ON THE ACCOUNTING INFORMATION QUALITY IN BRAZILIAN COMPANIES}

\section{LA INFLUENCIA DEL BOARD INTERLOCKING EN LA CALIDAD DE LA INFORMACIÓN CONTABLE EN EMPRESAS BRASILEÑAS}

Recebido em: 04/02/2019

Avaliado em: 15/04/2019

Reformulado em:30/04/2019

Aceito para publicação em: 14/06/2019

Publicado em: 03/07/2019

Editor Responsável: Tarcísio Pedro da Silva
Claudio Marcelo Edwards Barro ${ }^{1}$

Romualdo Douglas Colauto ${ }^{2}$

\section{RESUMO}

Esse estudo tem como objetivo examinar a influência do Board Interlocking sobre a Qualidade da Informação Contábil determinada a partir de um conjunto de métricas de Gerenciamento de Resultados, Tempestividade e Relevância da Informação Contábil denominada de Portfolio Approach proposta por Barth, Landsman e Lang (2008), adicionado do Conservadorismo Condicional. Neste estudo, postula-se que o poder de monitoramento de Conselheiros pode ser enfraquecido pelas múltiplas conexões entre Conselhos e Diretorias. Nessa direção, foram formuladas quatro hipóteses de que o Board Interlocking exerceria efeito negativo sobre a Qualidade da Informação Contábil aumentando o Gerenciamento de Resultados (H1), diminuindo o Conservadorismo (H2), a Tempestividade (H3) e a Relevância da Informação Contábil (H4). A população-alvo da pesquisa é o conjunto de empresas de capital aberto que divulgaram Formulários de Referência nos anos de 2010 a 2015 por meio do website da Comissão de Valores Mobiliários. Os resultados mostraram que 79,34\% das empresas abertas brasileiras realizaram Board Interlocking. Entretanto, somente $17,83 \%$ do contingente de mais de 6000 integrantes de Conselhos de Administração, Diretorias Executivas e Conselhos Fiscais formaram a totalidade das conexões no Brasil. Os principais resultados alcançados são de que Gerenciamento de Resultados, Conservadorismo e Tempestividade da informação contábil são indiferentes à incidência do Board Interlocking. No entanto, em favor da hipótese H4, foi possível observar maior Relevância da Informação Contábil ante a menor incidência de conexões.

Palavras-chave: Board Interlocking; Portfolio Approach; Sobrecarga.

\footnotetext{
${ }^{1}$ Doutor em Contabilidade pela Universidade Federal do Paraná (UFPR); Professor do Departamento de Contabilidade da Universidade Federal do Paraná (UFPR); E-mail: claudiomedwards@ hotmail.com

2 Pós-doutor em Contabilidade pela Universidade de São Paulo (USP); Doutor em Engenharia de Produção pela Universidade Federal de Santa Catarina (UFSC); Professor do Programa de Pós-Graduação em Contabilidade da Universidade Federal do Paraná (UFPR); E-mail: rdcolauto@gmail.com
} 


\section{ABSTRACT}

This study aims to examine the influence of Board Interlocking on the Quality of Accounting Information determined from a set of metrics of Earnings Management, Timeliness and Relevance of Accounting Information defined as Portfolio Approach and proposed by Barth, Landsman and Lang (2008), added by Conditional Conservatism. In this research, it is argued that the monitoring power of Directors may be weakened by multiple connections among companies. In this sense, it was formulated hypotheses that Board Interlocking would exert a negative effect on the Quality of Accounting Information, increasing Earnings Management (H1), reducing the Conservatism (H2), Timeliness (H3) and Relevance of Accounting Information (H4). The target population of the paper is the set of opened companies that issued Reference Forms in the years 2010 to 2015 through the website of the Brazilian Securities and Exchange Commission. It was presented that 79,34\% of the Brazilian open companies performed Board Interlocking. Nevertheless, only $17,83 \%$ of the contingent of more than 6.000 members of Boards of Directors, Executive Boards and Fiscal Councils formed the totality of the connections in Brazil. The main results observed are that the Earnings Management, Conservatism and Timeliness of accounting information are indifferent to the incidence of Board Interlocking. But, in favor of the $\mathrm{H} 4$ hypothesis, it was possible to observe a greater relevance of accounting information associated to lower incidence of connections.

Keywords: Board Interlocking. Portfolio Approach. Busyboard.

\section{RESUMEN}

Este estudio tiene como objetivo examinar la influencia del Board Interlocking sobre la Calidad de la Información Contable determinada a partir de un conjunto de métricas de Gestión de Resultados, Tempestividad y Relevancia de la Información Contable denominada de Portfolio Approach propuesta por Barth, Landsman y Lang (2008), agregado del Conservador Condicional. En este estudio, se postula que el poder de monitoreo de Consejeros puede ser debilitado por las múltiples conexiones entre Consejos y Directorios. En esa dirección, se formularon cuatro hipótesis de que el Board Interlocking ejercer un efecto negativo sobre la calidad de la información contable aumentando la gestión de resultados $(\mathrm{H} 1)$, disminuyendo el conservadurismo $(\mathrm{H} 2)$, la tempestividad $(\mathrm{H} 3)$ y la relevancia de la información contable (H4). La población objetivo de la investigación es el conjunto de empresas de capital abierto que divulgar formularios de referencia en los años de 2010 a 2015 a través del sitio web de la Comisión de Valores Mobiliarios. Los resultados mostraron que el 79,34\% de las empresas abiertas brasileñas realizaron Board Interlocking. Sin embargo, sólo el 17,83\% del contingente de más de 6000 integrantes de Consejos de Administración, Directorios Ejecutivos y Consejos Fiscales formaron la totalidad de las conexiones en Brasil. Los principales resultados alcanzados son que la Gestión de Resultados, Conservador y Tempestividad de la información contable son indiferentes a la incidencia del Board Interlocking. Sin embargo, en favor de la hipótesis $\mathrm{H} 4$, fue posible observar mayor Relevancia de la Información Contable ante la menor incidencia de conexiones.

Palabras clave: Board Interlocking. Portfolio Approach. Sobrecarga.

\section{INTRODUÇÃO}

Conselhos de Administração são órgãos de deliberação colegiada cujas competências envolvem o monitoramento de riscos e a orientação de executivos para maximização de retornos de investimentos corporativos (Hermalin, \& Weisbach, 1991; Fich, \&White, 2001; Adams, Hermalin, $\&$ Weisbach, 2010). No que concerne aos deveres de monitoramento ligados ao reporte de Demonstrações Financeiras, órgãos de regulação do Mercado de Capitais e organismos internacionais têm exaltado a responsabilidade de supervisão dos Conselhos de Administração. Para a Organização 
de Cooperação e de Desenvolvimento Econômico (OCDE) os Conselhos de Administração devem supervisionar o exercício das atividades de executivos de maneira a assegurar a integridade dos sistemas de contabilidade e de informação financeira da corporação com vistas à elevada qualidade do reporte financeiro.

O Financial Reporting Concil (FRC) no Reino Unido indica que as Demonstrações Financeiras devem passar pela supervisão do Conselho de Administração para que exista a ciência sobre as bases contábeis nas quais as demonstrações foram elaboradas (FRC, 2016). Recomendações semelhantes ligam os Conselhos de Administração às atribuições de "dever de cuidar" do reporte financeiro também no Canadá (Osler's Guide to Directors' responsability) e na Austrália e Nova Zelândia (Australian Institute of Company Directors e Directors' Responsibilities for Financial Reporting). No Brasil, a Lei 6404 de 1976 tornou obrigatório que Conselhos de Administração fiscalizem a gestão de diretores e examinem livros e papeis da companhia. A Comissão de Valores Mobiliários do Brasil defende que Conselhos de Administração devem ter em sua composição membros de notório conhecimento em finanças e contabilidade dada sua responsabilidade em compreender a sintaxe contábil de práticas adotadas (CVM, 2002).

A inquietação manifestada por reguladores e demais órgãos e instituições ao redor do mundo atravessou a barreira pragmático-normativa e progressos também foram observados no campo da pesquisa empírica direcionada a observar a influência de Conselhos de Administração sobre o conteúdo das Demonstrações Contábeis. A partir dos anos de 2000 investigações passaram a examinar com desvelo o impacto de características próprias de Conselhos de Administração como tamanho, longevidade e composição sobre aspectos da informação contábil, tais como, Gerenciamento de Resultados, Conservadorismo, Informatividade e Relevância da Informação Contábil (Vafeas, 2000; Klein, 2002; Beeks, Pope, \& Young, 2004; Ahmed, Houssain, \& Adams, 2006; Firth, Fung, \& Rui, 2007; Dimitropoulos, \& Asteriou, 2010; Alves, 2011; Holtz, \& Sarlo, 2014).

A Separação da Propriedade e Controle prevê que Conselheiros externos exerçam papel vital no monitoramento de Conselheiros internos e demais executivos da companhia. Fama e Jensen (1983) defendem que o incentivo para que conselheiros externos sejam vistos como exímios supervisores é o de que eles devem cuidar de sua reputação. No entanto, esse incentivo parece não ser o único a explicar o desempenho de indivíduos ocupantes de posições de conselheiros (Macavoy, \& Millstein, 2002), sobretudo quando se considera que Conselheiros externos podem, simultaneamente, ocupar posições em empresas diferentes como Conselheiros, como Diretores executivos ou ainda as duas posições, configurando a condição de Board Interlocking (Fich, \& White, 2001).

Embora o conjunto de argumentos teóricos desenvolvido por Fama e Jensen (1983) descreva os incentivos que norteiam a atuação dos Conselheiros outsiders, os possíveis desdobramentos da atuação simultânea de Conselheiros em mais de uma corporação foram deixados de lado na discussão teórica. Essa lacuna foi suprida por estudos empíricos que constataram limites para a capacidade de supervisão de Conselheiros outsiders envolvidos em Board Interlocking e o enfraquecimento de poder de vigilância de Conselhos de Administração com integrantes conectados. Evidências nessa direção podem ser observadas nos estudos que associam a atuação de Conselhos de Administração na manipulação de opções de ações (Bizjak, Lemmon, \& Whitby, 2009); circunstâncias envolvendo destruição de Valor em combinações de negócios (Cai, \& Sevilir, 2012; Ishii, \& Xuan, 2014); valoração acionária negativa e efeitos sobre o desempenho (Fich, \& Shividasani, 2006; Santos, \& Silveira, 2007; Mendes, 2011); perda de poder de monitoramento quando da intensificação de conexões entre conselheiros e CEO's (Fracassi, \& Tate, 2012), dentre outros.

Chiu, Teoh e Titan (2013) mostraram que conexões na alta administração servem também de veículo para a prática de manipulação de resultados contábeis. Evidenciaram que o Gerenciamento de Resultados se propaga de forma semelhante a um vírus, conferindo relação positiva entre a formação de Board Interlocking e o Gerenciamento de Resultados. Mostraram, portanto, que a Qualidade da Informação Contábil não passa incólume à interferência do ofício dos Conselhos de 
Administração conectados e seus achados concorreram para enfraquecer a ideia de que outsiders são exímios supervisores corporativos da informação financeira reportada ao mercado de capitais. Nos anos seguintes ao estudo de Chiu et al. (2013) surgiram tanto achados na mesma linha do autor (Chen, 2011; Baccouche, \& Omri, 2014; Shu, Yeh, Chiu, \& Yang, 2015) quanto estudos em direção contrária (Mindzak, 2013) e também evidências que podem ser considerados heterogêneas ao ponto de mostrar indícios de que o Board Interlocking pode ser tanto nocivo quanto saudável ao reporte financeiro (Hashim, \& Rahman, 2011; Felix, 2016), conferindo polarização à questão nos países em que o tema fora abordado.

Considerando corporações brasileiras de capital aberto, esse estudo tem como objetivo examinar a influência. do Board Interlocking sobre a Qualidade da Informação Contábil determinada a partir de um conjunto de métricas de Gerenciamento de Resultados, Tempestividade e Relevância da Informação Contábil denominada de Portfolio Approach proposta por Barth, Landsman e Lang (2008). Postula-se que o poder de monitoramento de Conselheiros pode ser enfraquecido pelas múltiplas conexões entre Conselhos e Diretorias em razão da imposição de limites para supervisão atenta de ações e decisões consideradas fundamentais para a condução exitosa de suas atribuições (Loderer, \& Peyer, 2002; Fich, \& Shivdasani, 2006; Santos, \& Silveria, 2007; Jiraporn, Davidson, Dadalt, \& Ning, 2009; Ahn et al. 2010; Cooper, 2012).

Esta pesquisa apresenta pelo menos duas contribuições. A primeira está em explorar a interferência de companhias conectados, tanto na forma do board interlocking propriamente dito como na forma de sobrecarga de conexões, sobre o conteúdo da informação contábil partilhado entre corporações brasileiras de capital aberto e usuários externos. Ressalte-se que a perspectiva de qualidade da informação contábil sustentada nessa investigação preocupa-se em utilizar um conjunto de métricas diversificado e consolidado no campo de estudos empíricos em contabilidade. Dessa forma, os achados que o estudo busca obter não estão restritos a medidas isoladas de qualidade informacional da contabilidade no Brasil.

Os vínculos que formam o Board Interlocking são representados por corporações. No entanto, conexões ocorrem preliminarmente entre indivíduos. Este estudo considerou a integralidade de conexões existentes em empresas brasileiras de capital aberto permitindo a mensuração exata de laços no nível da firma e no nível de integrantes de alta administração que compõem essas corporações. Nesse sentido, a contribuição desse trabalho realça o estudo da ligação entre o Board Interlocking e qualidade da informação contábil sem desprezar o alcance que conexões pode ter.

\section{DESENVOLVIMENTO DAS HIPÓTESES}

\subsection{Gerenciamento de Resultados}

Nas funções dos Conselhos de Administração estão aquelas genericamente definidas como Decisões de Controle. Beasly (1996) defende que funções de Decisão de Controle incluem o monitoramento da qualidade do reporte financeiro ao público. Por sua vez, Vafeas (2000) argumenta que os Conselhos de Administração são responsáveis em monitorar a qualidade da informação para evitar que gestores, por interesses individuais, manipulem resultados. Salienta ainda que características como o volume de Conselheiros e a presença de membros outsiders influenciam na capacidade de supervisão dos Conselhos em não deixar que o reporte financeiro seja deteriorado pelo exercício da discricionariedade do gestor. Evidências adicionais sobre o poder monitorador dos Conselhos de Administração em conter a discricionariedade gestor são mencionadas por Peasnell, Pope e Young (2000), Klein (2002), Sarkar, Sarkar e Sen (2008) e Geraldes (2011). Desse modo, o Conselho de Administração atua como um mecanismo limitador para ação potencialmente oportunista do Gestor.

Entretanto, em pesquisas que examinaram o desempenho dos Conselhos de Administração em contornar de problemas de agência há um subgrupo de estudos que realçam o Board Interlocking como um fenômeno extenuante da capacidade de monitoramento do Conselho sobre a 
discricionariedade da gestão (Loderer, \& Peyer, 2002; Fich, \& Shivdasani, 2006; Davidson et al., 2009; Ahn et al., 2010; Cooper, \& Uzum, 2010; Fracassi, \& Tate, 2002; Hallock, 1997; Fich, \& White, 2003; Larcker, Richardson, Seary, \& Tuna, 2005). Nessa mesma temática, também se incluem as investigações que evidenciaram a influência de Conselhos de Administração conectados sobre a manipulação de resultados contábeis, as quais conferiram tanto influência salutar do Board Interlocking sobre o Gerenciamento de Resultados (Norman, Takian, \& Mohd, 2005; Mindkak, 2013; Shu, Yeh, Chiu, \& Yang, 2015, Tham, Nigar, \& Harjinder, 2016; Javanshirinejad, \& Aghabeigi, 2016); como influência prejudicial (Markarian, \& Parbonetti, 2009; Felix, 2016.); e outros estudos que apesentaram resultados com interpretações em duas direções a exemplo de Hashim e Rahman (2011) que encontraram influência não-linear negativa do Board Interlocking sobre o nível de Gerenciamento de Resultados e Chiu et al. (2013) que mostraram a utilização do Board Interlocking tanto para propagação de políticas contábeis deterioradoras da Qualidade da Informação Contábil como para transmissão de práticas capazes de melhorar o reporte financeiro ao mercado de capitais.

Levando em consideração evidências nacionais e internacionais de que a exposição à sobrecarga de atribuições de executivos com participação em múltiplos Conselhos de Administração deterioraria o poder se supervisão dos Conselhos e que isso pode obstaculizar a capacidade dos Conselhos de supervisionar atos e decisões da gestão; e tendo em vista indícios de profusão de práticas de suavização de resultados em redes formadas por Conselheiros de empresas brasileiras (Ribeiro, \& Colauto, 2016), estabelece-se a seguinte hipótese:

H1: O Board Interlocking exerce influência negativa sobre a Qualidade da Informação Contábil aumentando o nível de Gerenciamento de Resultados de empresa brasileiras.

\subsection{Conservadorismo Contábil}

Watts (2003) argumenta que gestores têm incentivos para esconder perdas, pois temem ser desligados da função que ocupam. Ao admitir perdas ou reconhecer que aceitaram projetos de investimentos cujos fluxos de caixa apresentaram vieses de estimativas que o tornaram viáveis, gestores podem levar o Conselho de Administração, e até mesmo investidores, a requerer a remoção daqueles de suas posições. Expõe que o Conservadorismo restringe o comportamento oportunista porque equilibra o viés da informação gerada pela gestão, salientando-o como uma característica intermediadora capaz atenuar a assimetria de informação entre Conselhos de Administração e a Gestão.

A visão difundida por Watts (2003) sobre a incumbência dos Conselhos de Administração em preservar o reporte financeiro conservador corrobora o argumento de Hermalin e Weisbach (2001) quando estes defendem que a função econômica dos Conselhos de Administração consiste em ajudar as corporações a resolver problemas de conflitos de agência. Mesmo a despeito de imperfeições, assumem que os Conselhos de Administração representam parte da solução de mercado para os problemas contratuais da firma. Nessa linha, existem indícios que ligam características de Conselhos de Administração e o Conservadorismo contábil. Ahmed e Duellman (2007) mostraram existir relação negativa entre o Conservadorismo e a proporção de Conselheiros insiders. No entanto, essa relação se alterna para positiva ao se considerar Conselheiros externos, o que sugere ser a presença de Conselheiros não pertencentes à companhia um mecanismo de governança que potencializa o reporte financeiro conservador. Embora existam evidências de fraca relação entre a presença de conselheiros externos e o conservadorismo contábil (Beeks et al., 2004), parte significativa dos achados acompanham Ahmed e Duellman (2007), a exemplo de Garcia et al. (2007) e Dimitropoulos e Asteriou (2010).

$\mathrm{Na}$ linha de estudos que examinaram a interferência dos Conselhos de Administração sobre a qualidade da informação contábil, leva-se em consideração que parte das funções de Conselhos de Administração envolve o exercício da vigilância sobre a qualidade da informação contida no reporte 
financeiro, e que funções dos Conselhos podem ser prejudicadas pelo fenômeno Board Interlocking, estabelece-se a seguinte hipótese:

H2: O Board Interlocking exerce influência negativa sobre a Qualidade da Informação Contábil diminuindo o Conservadorismo contábil de empresas brasileiras.

\subsection{Tempestividade da Informação Contábil}

No Brasil, a Estrutura Conceitual para Elaboração de Demonstrações Contábeis define a Tempestividade como um atributo no qual a corporação disponibiliza a informação financeira ao tempo de torná-la oportunamente útil para decisões de seus usuários. No Pronunciamento Contábil, define-se a Tempestividade como uma característica qualitativa da informação contábil e enuncia que a informação mais antiga é sempre de menor utilidade. Entretanto, não desconsidera que determinados tipos de usuários podem necessitar avaliar os desdobramentos de informações geradas no passado em função da necessidade de avaliar tendências.

Tendo-se como premissa as evidências de estudos prévios nos quais umas das características do reporte de lucros de alta qualidade é que perdas são reconhecidas quando ocorrem, ao invés de serem diferidas ao longo de períodos sucessivos, e conforme discutido na segunda hipótese, que a revelação de resultados bons envolve um nível mais elevado de verificabilidade, pode-se argumentar que Tempestividade e o Conservadorismo são qualidades informacionais interligadas e intrínsecas.

Ao levar em conta que Gestores têm incentivos para esconder ou mascarar resultados ao ponto de influenciar a percepção de diversos destinatários da informação contábil e que o Conservadorismo contábil é um mecanismo potencialmente capaz de restringir o comportamento oportunista da gestão, é possível intuir que maior nível de Conservadorismo esteja ligado a maior nível de Tempestividade.

Almeida (2010) constatou que Tempestividade é um atributo observável nas Demonstrações Contábeis de empresas brasileiras. Mostrou que o nível de concentração de mercado tem efeito sobre a qualidade do reporte financeiro ao mercado de capitais. Também utilizando o Portfolio Approach proposto por Barth et al. 2008, evidenciou que quão mais elevado for o nível de concorrência, maior será a disciplina imposta pelos mercados às empresas competidoras em termos de escolhas contábeis, as quais se refletem na Tempestividade e Conservadorismo Contábil. Silva (2013) evidenciou que a adoção integral às normas internacionais de contabilidade no Brasil nos anos de 2010 e 2011 tornou as Demonstrações Contábeis mais tempestivas e, portanto, comparativamente mais oportunas no propósito de avaliar riscos e estabelecer estimativas mais precisas sobre o desempenho das corporações.

Ao levar com consideração que parte das funções de Conselhos de Administração envolve o exercício da vigilância sobre a qualidade da informação do reporte financeiro e que funções e composição dos Conselhos podem ser prejudicadas pelo fenômeno Board Interlocking, estabelece-se que:

H3: O fenômeno Board Interlocking exerce influência negativa sobre a Qualidade da Informação Contábil diminuindo a Tempestividade da informação contábil de empresas brasileiras.

\subsection{Relevância da Informação Contábil}

Barth et al. (p.78, 2001) argumentam que "pesquisas sobre Relevância da Informação Contábil podem se harmonizar às pesquisas relacionadas ao conservadorismo, sobretudo para estudar as implicações da relação entre valores contábeis e valores de mercado". Defendem que a pesquisa sobre Relevância da Informação Contábil é a base para se estabelecer que determinadas práticas de contabilidade financeira sejam percebidas por investidores como sendo conservadoras.

A compreensão relacionada aos fatores potencialmente capazes de explicar o aumento (ou diminuição) da Relevância da Informação Contábil passa também pela investigação da participação 
das corporações no processo de evidenciação da informação financeira ao usuário. Nessa linha de investigação, dada à concentração de autoridade e responsabilidade legal formalmente estabelecidas, os Conselhos de Administração se mostram como agentes de participação distinta.

Funções de Decisões de Gestão e Decisões de Controle são desempenhadas por Conselhos de Administração das corporações (Fama, \& Jensen, 1983). Partindo desse poder de deliberação e delegação, espera-se que a diligência dos Conselhos de Administração alcance o processo de geração e reporte de informações financeiras. Sob a perspectiva do reporte financeiro, uma consequência desejável de governança corporativa é a expectativa de alta na Qualidade da Informação Contábil (Habib, \& Azim, 2008). Especificamente, espera-se que quando Conselhos de Administração apresentam desempenho eficaz no processo de monitoramento da gestão e que os valores contábeis guardem correlação ao preço das ações, mostrando-se úteis ao investidor.

Vafeas (2000) evidencia que a capacidade informativa dos lucros sobre o retorno das ações se torna uma relação mais pronunciada em corporações cujos Conselhos de Administração são menos numerosos, embora não tenha observado a mesma intensidade ao examinar o poder de moderação de conselheiros outsides nessa relação. Habib e Azim (2008) evidenciaram que a Relevância da Informação Contábil é influenciada pelo tamanho do Conselho de Administração e, diferente de Vafeas (2000), observaram que a independência do Conselho tem efeito sobre a Relevância da Informação Contábil. Embora seja possível encontrar resultados contrários (Alkdai E Hanefah, 2012), as evidências apontam majoritariamente que características estruturais dos Conselhos de administração afetam significativamente a relação entre saldos contábeis e preços de ações, tornado, portanto a informação contábil mais útil ao investidor (Ahmed, Hossim, \& Adams, 2006; Firth, Fung, \& Rui, 2007; Holtz, \& Sarlo Neto, 2014).

Nessa direção, Bae e Jeong (2007) mostraram que a presença de acionistas com participação simultânea no capital de companhias pertencentes ao mesmo conglomerado econômico afeta negativamente a Relevância da Informação Contábil. Os autores evidenciaram que a força de associação entre o lucro (e patrimônio líquido) e o preço das ações de empresas pertencentes a grupos econômicos, cujos acionistas estejam conectados, é menor se comparado a empresas que não pertencem a conglomerados. Bae e Jeong (2007) sugeriram que investidores dedicam menos atenção à informação contábil reportada porque eles observam que o reporte financeiro de conglomerados com proeminente conectividade reflete interesses próprios de acionistas com elevado poder de influência, e não a realidade subjacente aos negócios da corporação. Como consequência, a intensidade dessas conexões exerceria poder de deteriorar a Relevância da Informação Contábil. Assim, estabelece-se que:

H4: O fenômeno Board Interlocking exerce influência negativa sobre a Qualidade da Informação Contábil diminuindo a Relevância da Informação Contábil de empresas brasileiras.

\section{AMOSTRA, DADOS E MÉTODOS}

\subsection{População e Amostra de Pesquisa}

A população-alvo da pesquisa é o conjunto de empresas de capital aberto que divulgaram Formulários de Referência (FR) nos anos de 2010 a 2015 por meio do website da Comissão de Valores Mobiliários. Há dois motivos para seleção desse espaço de tempo. A primeira é que esse intervalo representa período de adoção integral de padrões internacionais de divulgação das Demonstrações Contábeis (IFRS) as quais são fonte para determinação das variáveis do constructo de Qualidade da Informação Contábil e parte significativa das Variáveis de Controle da pesquisa, deixando, portanto, as variáveis contábeis construídas sob uma mesma base. Além disso, embora as companhias brasileiras abertas estivessem obrigadas a emitir Formulário de Referência em arquivos avulsos a partir de 2009, foi a partir de 2010 que a plataforma da CVM denominada EmpresasNet ficou disponível. Essa plataforma evidencia no item 12 (Assembleia e administração) e no subitem 12.5 e 
12.6, o detalhamento dos nomes de todos os membros que compõem Conselhos de Administração, Diretorias e Conselhos Fiscais. Assim, a partir dessa plataforma foi possível operar todas as conexões no nível da firma e no nível de integrantes.

Em relação à população e a formação de amostras, a realização das análises se dividiu em duas fases ${ }^{3.8}$. Na primeira fase, fez-se um exame descritivo das empresas brasileiras que entre $2010 \mathrm{e}$ 2015 divulgaram Formulários de Referência. O objetivo foi obter um panorama sobre a formação completa de conexões entre empresas brasileiras a partir de integrantes dos Conselhos de Administração, Diretorias Executivas e também de Conselhos Fiscais cias, constituindo-se em um censo do Board Interlocking no Brasil. Ressalte-se que Conselhos Fiscais foram incluídos em razão da existência de integrantes que também ocuparam posição no Conselho de Administração ou na Diretoria em outras empresas da população. Na Tabela 1 mostra-se a composição da população do estudo.

Tabela 1 - Empresas que divulgaram Formulário de Referência (FR) entre de 2010 a 2015

\begin{tabular}{ccccccc}
\hline Ano & $\mathbf{2 0 1 0}$ & $\mathbf{2 0 1 1}$ & $\mathbf{2 0 1 2}$ & $\mathbf{2 0 1 3}$ & $\mathbf{2 0 1 4}$ & $\mathbf{2 0 1 5}$ \\
\hline Total de Empresas & 647 & 667 & 663 & 647 & 646 & 633 \\
\hline
\end{tabular}

Nota. Total de Empresas: descreve a quantidade de empresas que divulgaram Formulário de Referência. Empresas identificadas por meio no CNPJ (Cadastro Nacional de Pessoa Jurídica) no website da CVM. Média-ano de empresas: 650,5 .

Para cada um dos anos do estudo foram construídas rotinas de programação para a contagem, as quais tornaram possível a observação do nome de totalidade dos integrantes que compuseram os Conselhos de Administração, Diretorias Executivas e Conselhos Fiscais das empresas descritas na Tabela 1. Para a identificação da formação do Board Interlocking entre as empresas, foi desenvolvido um algoritmo que permitiu a identificação de ocupação simultânea de integrantes desses Órgãos de Administração. Essas rotinas possibilitaram a demonstração da quantidade de conexões no nível de empresas e no nível de integrantes para todo o período.

$\mathrm{Na}$ segunda fase, coletaram-se dados contábeis e preços de ações para a determinação das métricas do Portfolio Approach proposto por Barth et al. (2008). Foram também coletados dados necessários para a computação do Modelo de Conservadorismo Condicional (Ball e Shivakumar, 2005). As empresas que compuseram o estudo foram todas as companhias de setores não financeiros com dados disponíveis para determinação das variáveis de pesquisa de 2010 a 2015. Para coleta de

Tabela 2 - Amostra da Pesquisa

\begin{tabular}{|c|c|c|c|c|c|c|c|c|}
\hline & 2008 & 2009 & 2010 & 2011 & 2012 & 2013 & 2014 & 2015 \\
\hline Total de Empresas & 454 & 463 & 472 & 499 & 517 & 533 & 533 & 578 \\
\hline ( - ) Setor Financeiro & -62 & -74 & -77 & -84 & -89 & -92 & -91 & -103 \\
\hline ( - ) Dados Contábeis indisponíveis & -137 & -135 & -130 & -122 & -103 & -105 & -93 & -107 \\
\hline ( - ) Outliers & -18 & -25 & -18 & -16 & -20 & -22 & -19 & -18 \\
\hline Subtotal (Dados Contábeis) & 237 & 229 & 247 & 277 & 305 & 314 & 330 & 350 \\
\hline ( - ) Sem cotações & -115 & -105 & -108 & -136 & -150 & -148 & -159 & -186 \\
\hline Total (Dados Contábeis e de cotações) & 122 & 124 & 139 & 141 & 155 & 166 & 171 & 164 \\
\hline
\end{tabular}

Nota. Setor financeiro: indica o total de companhias do setor bancário, seguros, fundos e outros serviços financeiros diversificados. Dados contábeis indisponíveis: mostra a quantidade de empresas sem as demonstrações de dados contábeis necessários para a determinação das variáveis de pesquisa e com patrimônio líquido negativo. Outliers: exclusão univariada de observações anuais acima de 3 desvios-padrão ou abaixo de -3 desvios-padrão. Subtotal: descreve a quantidade de empresas com dados contábeis disponíveis. Sem cotações: evidenciam a total de empresas sem cotações nos seus preços de ações. Média-ano de empresas com dados contábeis: 304,8. Média-ano de empresas com dados contábeis e cotações: 158,3 .

dados foram utilizados os sistemas Economática® e Bloomberg ${ }^{\circledR}$. A amostra da pesquisa está descrita na Tabela 2 a qual mostra a contagem de observações que serviram de base para a estimação dos parâmetros direcionados a examinar a influência do Board Interlocking sobre as medidas de 
Gerenciamento de Resultados, Conservadorismo Contábil, Tempestividade e Relevância da Informação contábil.

Mostra-se na Tabela 2 que as empresas financeiras foram excluídas. Essa exclusão ocorreu porque no conjunto de variáveis de controle que formam os Modelos do Portfólio Approach proposto por Barth et al. (2008) constam variáveis que não podem ser mensuradas para, por exemplo, empresas do setor bancário ou de seguros. Empresas do setor financeiro têm planos de contas diferentes de empresas que atuam em setores não financeiros e em decorrência dessa diferença a mensuração de determinadas variáveis fica impossibilitada. Exemplos dessas variáveis são o crescimento da dívida (EISSUE), determinada pela variação percentual anual do passivo oneroso de empresas, e endividamento $(L E V)$ calculado pela razão entre o passivo oneroso e patrimônio líquido.

A Tabela 2 apresenta duas identificações que servem para mostrar a quantidade de empresas amostradas a considerar o tipo de métrica do Portfolio Approach. Considerando que Relevância da Informação Contábil lida especificamente com preços de ações, companhias sem cotações de preço (linha "Sem cotações") de suas ações não poderiam ser examinadas. As outras métricas do Portfolio Approach e também as métricas do conservadorismo envolvem exclusivamente dados contábeis (linha "Dados Contábeis").

Deve-se ressaltar que as duas fases descritas nessa seção possibilitaram que as conexões entre companhias e integrantes fossem contabilizadas na sua integralidade quando da utilização da população de empresas de capital aberto de 2010 a 2015. Essa medida indica que a contagem de laços entre integrantes e companhias não foi subavaliado quando da condução da análise da influência do board interlocking sobre a qualidade da informação contábil para a amostra de companhias descritas na Tabela 2.

Ainda na segunda fase, foram consideradas somente empresas que durante os anos de estudo apresentassem pelo menos 3 anos de dados anuais consecutivos, constituindo-se em uma estrutura de dados em painel na variante desbalanceada. A utilização de painéis desbalanceados é comum na pesquisa contábil e eles podem ser observados em duas investigações de referência para a realização desse estudo (Fich, \& Shivdasani, 2006; e Barth et al. 2008). ${ }^{2.7}$

\subsection{Variáveis para o Board Interlocking}

A construção das variáveis para determinação de Board Interlocking é definida por meio de elementos constitutivos de redes sociais corporativas. No Quadro 1 apresentam-se as definições dessas métricas.

Em relação a variável $B I_{i t}$, como resultado dessa identificação, observou-se que companhias cujos integrantes tinham dedicação exclusiva aos seus Boards e companhias que compartilharam 1 ou mais integrantes ao longo dos anos do estudo. A segunda medida, DEGREE_LN $i$, decorre da utilização do indicador de Centralidade em Grau extraído do software UCINET® a qual considera a quantidade de conexões entre as empresas analisadas. Esta métrica se refere à centralidade de um vértice $\left(v_{k}\right)$ e está relacionada a contagem da quantidade de contatos diretos que uma determinada unidade (empresa) possui. A centralidade de grau de um vértice $v_{k}$ é identificada por $d_{k}$ e representa o que em análise de redes é dado pelo número total de arestas incidentes no vértice $v_{k}$.

No entanto, foi observado que as conexões entre empresas ocorrem por intermédio de pessoas que estão presentes nessas conexões, sobretudo em Conselhos de Administração e Diretorias. Logo, a determinação da quantidade de laços entre empresas se tornou possível porque primeiro se mediu a quantidade de pessoas envolvidas nessas conexões. Então, para não ignorar a quantidade de integrantes que formam as conexões entre as empresas, o resultado do indicador de Centralidade em Grau resultante da contagem de empresas conectadas foi ponderado pelo logaritmo natural da quantidade de integrantes envolvidos naquela conexão. 
Quadro 1 - Medidas de Caracterização do Board Interlocking de empresas brasileiras

\begin{tabular}{|c|c|c|c|c|}
\hline Variável & $\begin{array}{l}\text { Tipo da } \\
\text { Variável }\end{array}$ & $\begin{array}{c}\text { Definição } \\
\text { constitutiva }\end{array}$ & Definição operacional & Referências \\
\hline $\begin{array}{l}\text { Constatação de } \\
\text { Board } \\
\text { Interlocking }\left(B I_{i t}\right)\end{array}$ & Independente & Dummy & $\begin{array}{l}\text { Variável que assume o valor " } 1 \text { " para } \\
\text { companhias que compartilham } \\
\text { executivos e "0" para aquelas que não } \\
\text { compartilham. }\end{array}$ & $\begin{array}{l}\text { Dooley (1969); } \\
\text { Fich e White } \\
\text { (2005) e Mizruchi } \\
(1996)\end{array}$ \\
\hline $\begin{array}{l}\text { Centralidade de } \\
\text { Grau } \\
\left(D E G R E E \_L N_{i t}\right)\end{array}$ & Independente & $C g\left(v_{i t}\right)=\frac{d\left(n_{i}\right)}{n-1}$ & $\begin{array}{l}\text { Medida utilizada para determinar a } \\
\text { quantidade de laços adjacentes de um } \\
\text { participante com outro participante } \\
\text { do Conselho de Administração. }\end{array}$ & $\begin{array}{l}\text { Mendes-da-Silva } \\
\text { (2011); Ribeiro e } \\
\text { Colauto (2016); } \\
\text { Felix (2016) }\end{array}$ \\
\hline $\begin{array}{l}\text { Sobrecarga de } \\
\text { Conselhos de } \\
\text { Administração } \\
\left(B I S_{i t}\right)\end{array}$ & Independente & Dummy & $\begin{array}{l}\text { Variável que assume o valor "1" } \\
\text { quando } 50 \% \text { ou mais do Conselho de } \\
\text { Administração ocupa } 3 \text { ou mais } \\
\text { posições simultaneamente, incluindo } \\
\text { a contagem da empresa de referência. }\end{array}$ & $\begin{array}{l}\text { Loderer e Peyer } \\
\text { (2002); Fich e } \\
\text { Shivdasani } \\
\text { (2006); Santos e } \\
\text { Miceli (2007) } \\
\end{array}$ \\
\hline $\begin{array}{l}\text { Sobrecarga de } \\
\text { Conselheiros } \\
\left(B I S P E R_{i t}\right)\end{array}$ & Independente & $\begin{array}{l}\text { Métrica em } \\
\text { percentual }\end{array}$ & $\begin{array}{l}\text { Percentual de Integrantes do } \\
\text { Conselho de Administração que } \\
\text { ocupam } 3 \text { ou mais posições } \\
\text { simultaneamente, incluindo a } \\
\text { contagem da empresa de referência. }\end{array}$ & $\begin{array}{l}\text { Loderer e Peyer } \\
\text { (2002); Fich e } \\
\text { Shivdasani } \\
\text { (2006); Santos e } \\
\text { Miceli (2007) }\end{array}$ \\
\hline
\end{tabular}

Fonte: Elaborado pelos autores

A terceira e quarta métrica foram determinadas com o objetivo de obter medidas sobre a Sobrecarga na alta administração. A medida descrita por $B I S_{i t}$ é uma dummy que identifica empresas cujos Boards tenham mais de 50\% dos seus integrantes atrelados em 3 ou mais empresas. Entretanto, para encontrar esse percentual foi necessário conhecer a condição de ocupação de cada integrante descrito no formulário de referência de cada uma das corporações estudadas no período estudado. Como consequência dessa determinação, foi possível observar a condição de cada integrante e relativizá-la perante os demais e, portanto, cada empresa, apresentou um percentual de integrantes do Board que ocupam 3 ou mais posições, simultaneamente descrita por BISPER $R_{i t}$.

\subsection{Variáveis de controle}

As variáveis de controle utilizadas no presente estudo estão em concordância com aquelas que compõem o Portfolio Approach proposto por Barth et al., 2008 e presentes nos modelos de gerenciamento de resultados e tempestividade da informação contábil. Essas variáveis são: $i)$ TAMit que representa o porte das corporações, dado pela extração do logaritmo natural dos ativos totais das companhias $i$ no tempo $t$; ; ii) GROW $W_{i t}$ determinado pelo crescimento anual da receita liquida das companhias $i$ no tempo $t$.; iii) $E I S S U E_{i t}$ calculado por meio da variação anual da quantidade de ações emitidas pelas companhias $i$ no tempo $t$.; iv) $L E V_{i t}$ que descreve o endividamento das companhias $i$ no tempo $t$ pela razão entre a dívida onerosa de curto e longo prazo e o Patrimônio Líquido; $v$ ) $D I S S U E_{i t}$ obtido por meio da variação anual do valor da dívida onerosa de curto e longo prazo das

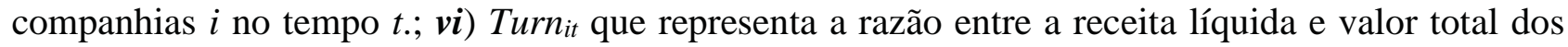
ativos anuais das companhias $i$ no tempo $t$.; vii) $C F_{i t}$ determinado pela razão do fluxo de caixa das operações e ativos totais anuais das companhias $i$ no tempo $t$; viii) $A U D_{i}$ : Variável dummy que o assume o valor de " 1 " caso a empresa seja auditada por uma das 4 maiores empresas do mundo de Auditoria Externa (Ernst Young, KPMG, PriceWaterhouseCooper e Delloite) e valor "0" para outras empresas de auditoria; $\boldsymbol{i x}$ ) $A G E_{i t}$ : idade da companhia i no tempo t calculada pelo Número de anos contados a partir da data que a empresa divulgou demonstrações contábeis pela primeira vez. 


\section{ANÁLISE DOS RESULTADOS}

\subsection{Empresas e integrantes envolvidos e não envolvidos em Board Interlocking}

$\mathrm{Na}$ Tabela 3 apresenta-se a distribuição de frequência absoluta e relativa de companhias que divulgaram informações anuais sobre a composição dos Conselhos de Administração, Diretorias Executivas e Conselhos Fiscais. As análises conduzidas nessa subseção consideram a integralidade das conexões existentes no nível da firma e no nível de integrantes e se referem a primeira fase delineada na seção 3.2.

Tabela 3 - Empresas envolvidas e não envolvidas em Board Interlocking

\begin{tabular}{cccccccccccccc}
\hline \multirow{2}{*}{ Empresas } & \multicolumn{2}{c}{$\mathbf{2 0 1 0}$} & \multicolumn{2}{c}{$\mathbf{2 0 1 1}$} & \multicolumn{2}{c}{$\mathbf{2 0 1 2}$} & \multicolumn{2}{c}{$\mathbf{2 0 1 3}$} & \multicolumn{2}{c}{$\mathbf{2 0 1 4}$} & \multicolumn{2}{c}{$\mathbf{2 0 1 5}$} \\
\cline { 2 - 14 } & $\boldsymbol{f}_{\boldsymbol{a}}$ & $\boldsymbol{f}_{\mathbf{r}}$ & $\boldsymbol{f}_{\boldsymbol{a}}$ & $\boldsymbol{f}_{\mathbf{r}}$ & $\boldsymbol{f}_{\boldsymbol{a}}$ & $\boldsymbol{f}_{\boldsymbol{r}}$ & $\boldsymbol{f}_{\boldsymbol{a}}$ & $\boldsymbol{f}_{\boldsymbol{r}}$ & $\boldsymbol{f}_{\boldsymbol{a}}$ & $\boldsymbol{f}_{\boldsymbol{r}}$ & $\boldsymbol{f}_{\boldsymbol{a}}$ & $\boldsymbol{f}_{\boldsymbol{r}}$ \\
\hline $\boldsymbol{S B I}$ & 150 & $23 \%$ & 99 & $15 \%$ & 144 & $22 \%$ & 133 & $21 \%$ & 134 & $21 \%$ & 149 & $24 \%$ \\
$\boldsymbol{C B I}$ & 497 & $77 \%$ & 568 & $85 \%$ & 519 & $78 \%$ & 514 & $79 \%$ & 512 & $79 \%$ & 484 & $76 \%$ \\
\hline Total de Cias. & \multicolumn{2}{c}{647} & \multicolumn{2}{c}{667} & \multicolumn{2}{c}{663} & & 647 & & 646 & 633 \\
\hline
\end{tabular}

Nota: SBI: empresas sem Board Interlocking; CBI: empresas com Board Interlocking. Em média, 516 companhias envolveram-se em Board Interlocking e 135 não. O desvio padrão do número de companhias que se envolveram e que não se envolveram em Board Interlocking foi de 29 e 19, respectivamente. O coeficiente de variação, dado pela razão entre media e desvio padrão, do número de companhias que se envolveram e que não se envolveram em Board Interlocking foi de $5,56 \%$ e $14,08 \%$, respectivamente.

Observa-se que, em média, 516 empresas realizaram conexões com outras empresas no Brasil com dispersão de 26 companhias. Ao se considerar que o coeficiente de variação ficou em 5,56\%, constata-se modesta oscilação da quantidade empresas envolvidas em Board Interlocking no período pesquisado. Embora a extração dos dados que formaram a Tabela 3 tenha-se derivado da totalidade das empresas brasileiras, é possível perceber que as frequências relativas das empresas com Board Interlocking apresentam proporções pouco variantes, convergindo para os resultados obtidos na pesquisa de Santos e Silveira (2007), mesmo que o estudo daqueles autores tenha considerado apenas as empresas com nível de liquidez acima de 0,1\% (319 empresas) para os anos de 2003 (74\%) e 2005 $(64,8 \%)$. Nesse estudo, com praticamente o dobro de empresas, $79,24 \%$ das companhias se envolveram em Board Interlocking.

Um ponto que merece destaque é à totalidade de integrantes que compuseram os Órgãos de Administração, conforme apresentado na Tabela 4.

Tabela 4 - Frequências de integrantes envolvidos e não envolvidos em Board Interlocking

\begin{tabular}{|c|c|c|c|c|c|c|c|c|c|c|c|c|}
\hline \multirow{2}{*}{$\begin{array}{l}\text { Número de } \\
\text { Integrantes }\end{array}$} & \multicolumn{2}{|c|}{2010} & \multicolumn{2}{|c|}{2011} & \multicolumn{2}{|c|}{2012} & \multicolumn{2}{|c|}{2013} & \multicolumn{2}{|c|}{2014} & \multicolumn{2}{|c|}{2015} \\
\hline & $f_{a}$ & $f_{r}$ & $f_{a}$ & $f_{r}$ & $f_{a}$ & $f_{r}$ & $f_{a}$ & $f_{r}$ & $f_{a}$ & $f_{r}$ & $f_{a}$ & $f_{r}$ \\
\hline$S B I$ & 4830 & $83 \%$ & 5171 & $82 \%$ & 5085 & $82 \%$ & 4991 & $82 \%$ & 5005 & $82 \%$ & 4861 & $82 \%$ \\
\hline$C B I$ & 1012 & $17 \%$ & 1097 & $18 \%$ & 1095 & $18 \%$ & 1092 & $18 \%$ & 1107 & $18 \%$ & 1095 & $18 \%$ \\
\hline $\mathbf{n}^{\mathbf{o}}$ de integrantes & \multicolumn{2}{|c|}{5842} & \multicolumn{2}{|c|}{6268} & \multicolumn{2}{|c|}{6180} & \multicolumn{2}{|c|}{6083} & \multicolumn{2}{|c|}{6112} & \multicolumn{2}{|c|}{5956} \\
\hline
\end{tabular}

Nota: SBI: integrantes sem Board Interlocking; CBI: integrantes com Board Interlocking. Em média, 1083 integrantes envolveram-se em Board Interlocking e 4991 não. O desvio padrão do número de integrantes que se envolveram e que não se envolveram em Board Interlocking foi de 35 e 130, respectivamente. O coeficiente de variação, dado pela razão entre media e desvio padrão, do número de integrantes que se envolveram e que não se envolveram em Board Interlocking foi de $2,4 \%$ e $3,0 \%$, respectivamente. A extração de nomes para a construção da base de dados ao nível de integrantes foi realizada desconsiderando a repetição de nomes nos Conselhos de Administração, Diretorias Executivas e Conselhos Fiscais $^{3.16}$.

Ao mostrar a ausência e presença de Board Interlocking, pode-se observar uma inversão de proporções. A Tabela 3 mostrou que a quantidade de corporações que realizam Board Interlocking é proporcionalmente maior que o número das que não o fizerem, sendo essa proporção diametralmente alterada quando se considera a quantidade de integrantes que realizam conexões, conforme mostra a Tabela 4. Constata-se que, da média de 6074 diferentes nomes, 4991 apresentaram dedicação 
exclusiva às companhias em que trabalhavam e somente 1083 envolveram em Board Interlocking. Nessas duas situações, a dispersão de integrantes é pequena (118 e 32 integrantes, respectivamente) apresentando diminuto coeficiente de variação nos dois casos com 3,0\% e 2,4\%. Ao longo dos anos seguintes, praticamente inexistiram oscilações nas proporções daqueles que apresentam elos com outras companhias.

Embora existam diferenças pronunciadas em termos de proporções de empresas e integrantes conectados e semelhanças em termos de fixidez dessas proporções ao longo dos anos, as descrições das Tabelas 3 e 4 sugerem existência de uma elite profissional relativamente restrita, minoritária e com dominante capacidade de influenciar decisões, além de dever obrigações de monitoramento sobre o desempenho econômico e financeiro das corporações que representam. Essas constatações ampliam os argumentos indicados por Santos e Silveira (2007) quanto à existência no Brasil de uma classe empresarial hegemônica proveniente do acúmulo de posições de alta administração e da ampliação de contatos sociais para compartilhamento de práticas corporativas de interesse comum.

\subsection{Sobrecarga}

Operacionalmente não é possível medir essa variável no nível de empresas sem primeiro computar a quantidade de integrantes conectados a cada uma das empresas da população. Os procedimentos de contagem envolvem necessariamente a determinação da possível sobrecarga de cada integrante do universo. Na Tabela 5 descrevem-se a quantidade de integrantes que se envolveram em sobrecarga.

Tabela 5 - Frequências de integrantes envolvidos e não envolvidos em sobrecarga

\begin{tabular}{|c|c|c|c|c|c|c|c|c|c|c|c|c|}
\hline \multirow{2}{*}{$\begin{array}{l}\text { Número de } \\
\text { Integrantes }\end{array}$} & \multicolumn{2}{|c|}{2010} & \multicolumn{2}{|c|}{2011} & \multicolumn{2}{|c|}{2012} & \multicolumn{2}{|c|}{2013} & \multicolumn{2}{|c|}{2014} & \multicolumn{2}{|c|}{2015} \\
\hline & $f_{a}$ & $f_{r}$ & $f_{a}$ & $f_{r}$ & $f_{a}$ & $f_{r}$ & $f_{a}$ & $f_{r}$ & $f_{a}$ & $f_{r}$ & $f_{a}$ & $f_{r}$ \\
\hline Sem sobrecarga & 563 & $56 \%$ & 619 & $56 \%$ & 632 & $58 \%$ & 613 & $56 \%$ & 643 & $58 \%$ & 664 & $60 \%$ \\
\hline Com sobrecarga & 449 & $44 \%$ & 478 & $44 \%$ & 463 & $42 \%$ & 479 & $44 \%$ & 464 & $42 \%$ & 431 & $39 \%$ \\
\hline Total & \multicolumn{2}{|c|}{1012} & \multicolumn{2}{|c|}{1097} & \multicolumn{2}{|c|}{1095} & \multicolumn{2}{|c|}{1092} & \multicolumn{2}{|c|}{1107} & \multicolumn{2}{|c|}{1095} \\
\hline
\end{tabular}

Nota. Em média, 622 integrantes não apresentaram sobrecarga e 461, sim. O desvio padrão do número de integrantes que não apresentaram e que apresentaram sobrecarga foi de 31 e 17, respectivamente. O coeficiente de variação do número de integrantes que não apresentaram e que apresentaram problema de sobrecarga foi de 5,03\% e 3,62\%, respectivamente ${ }^{3.16}$.

Em média, a quantidade de integrantes envolvidos em sobrecarga ficou em 461 integrantes com dispersão de 17 indivíduos, levando a um coeficiente de variação de 3,62\% revelando baixa oscilação no número de integrantes conectados a três empresas ou mais. Ao levar em consideração dos dados da Tabela 4, a proporção de integrantes sobrecarregados em relação ao total de indivíduos que compuseram os Órgãos de Administração de companhias abertas no período foi de somente de 7,58\% e com módica oscilação longo dos anos da série, ampliando os indícios de que o fenômeno do Board Interlocking no Brasil é protagonizado por número pequeno e concentrado de indivíduos, o que por sua vez corrobora a ideia de que a alta administração das companhias brasileiras recebe importante influência de grupos hegemônicos. Na Tabela 6 demonstram-se as frequências das empresas que realizaram Board Interlocking cujos integrantes envolveram-se em sobrecarga.

Tabela 6 - Frequências de empresas envolvidas e não envolvidos em Sobrecarga

\begin{tabular}{|c|c|c|c|c|c|c|c|c|c|c|c|c|}
\hline \multirow{2}{*}{$\begin{array}{l}\text { Número de } \\
\text { Empresas }\end{array}$} & \multicolumn{2}{|c|}{2010} & \multicolumn{2}{|c|}{2011} & \multicolumn{2}{|c|}{2012} & \multicolumn{2}{|c|}{2013} & \multicolumn{2}{|c|}{2014} & \multicolumn{2}{|c|}{2015} \\
\hline & $f_{a}$ & $f_{\mathrm{r}}$ & $f_{a}$ & $f_{\mathrm{r}}$ & $f_{a}$ & $f_{r}$ & $f_{a}$ & $f_{r}$ & $f_{a}$ & $f_{r}$ & $f_{a}$ & $f_{r}$ \\
\hline Sem sobrecarga & 110 & $22,1 \%$ & 83 & $14,6 \%$ & 97 & $18,7 \%$ & 91 & $17,7 \%$ & 101 & $19,7 \%$ & 107 & $22,1 \%$ \\
\hline Com Sobrecarga & 387 & $77,9 \%$ & 485 & $85,4 \%$ & 422 & $81,3 \%$ & 423 & $82,3 \%$ & 411 & $80,3 \%$ & 377 & $77,9 \%$ \\
\hline Total de empresas & & 97 & & & & 9 & & 4 & & 2 & & 84 \\
\hline
\end{tabular}

Nota: Sem sobrecarga: totalidade de integrantes ligados a no máximo duas empresas simultaneamente. Com Sobrecarga: totalidade de integrantes ligados a 3 ou mais empresas, simultaneamente. 
Nota-se que dentre as empresas que realizaram Board Interlocking, 80,84\% tiveram em seu Board pelo menos 1 integrante envolvido em sobrecarga, denotando que um número consideravelmente pequeno de profissionais que acumularam funções na grande maioria das empresas brasileiras. Em termos comparativos, a sobrecarga no nível de integrantes $(42,56 \%$, Tabela 5) é proporcionalmente menor do que no nível das corporações.

A computação de dados necessária para resumo de frequências nas Tabelas 5 e 6 tornou possível a determinação da quantidade de posições ocupadas por cada integrante e, consequentemente, viabilizou a determinação do percentual de integrantes do Board que, simultaneamente, estiveram presentes em 3 ou mais companhias. Assim, a estrutura de dados resultante, além de possibilitar a identificação das empresas que estavam na condição de sobrecarga, conforme Fich e Shivdasani (2006), também viabilizou a determinação do percentual de sobrecarga para cada uma das companhias.

\subsection{Board Interlocking e Qualidade da Informação Contábil}

Nesta etapa são demonstradas as principais equações e todos os resultados dos estimadores dos 23 modelos utilizados para examinar as hipóteses de influência do Board Interlocking sobre a Qualidade da Informação Contábil. Com o objetivo de identificar os resultados das estimações de cada um desses modelos de análise e orientar a interpretação desses resultados, apresenta-se o Quadro 2 .

Quadro 2 - Direções para Interpretação das métricas por Portfolio Approach de Barth et al. (2008)

\begin{tabular}{|c|c|c|c|}
\hline Métricas & Tipo & Descrição & Interpretação \\
\hline \multirow{2}{*}{$\Delta N I$} & \multirow{2}{*}{$\begin{array}{l}\text { Suavização de Resultados } \\
\text { (Modelos 1, 4, } 7 \text { e 10) }\end{array}$} & Aumento na variância de $\Delta N I$ & $<\mathrm{GR}>\mathrm{QIC}$ \\
\hline & & Diminuição na variância de $\Delta N I$ & $>\mathrm{GR}<\mathrm{QIC}$ \\
\hline \multirow{2}{*}{$\triangle N I / \triangle C F$} & \multirow{2}{*}{$\begin{array}{l}\text { Suavização de Resultados } \\
\text { (Modelos 2, 5, } 8 \text { e 11) }\end{array}$} & Aumento na variância de $\triangle N I / \Delta C F$ & $<\mathrm{GR}>\mathrm{QIC}$ \\
\hline & & Diminuição na variância de $\Delta N I / \Delta C F$ & $>\mathrm{GR}<\mathrm{QIC}$ \\
\hline \multirow{2}{*}{$S P O S$} & \multirow{2}{*}{$\begin{array}{l}\text { Suavização de Resultados em } \\
\text { direção a pequenos lucros } \\
\text { (Modelos } 3,6,9 \text { e 12) }\end{array}$} & Baixa frequência de pequenos lucros & $<\mathrm{GR}>\mathrm{QIC}$ \\
\hline & & Alta frequência de pequenos lucros & $>\mathrm{GR}<\mathrm{QIC}$ \\
\hline \multirow{2}{*}{$L N E G$} & \multirow{2}{*}{$\begin{array}{l}\text { Tempestividade }(16,17,18 \mathrm{e} \\
19)\end{array}$} & Alta frequência de grandes prejuízos & > Tempe. > QIC \\
\hline & & Baixa frequência de grandes prejuízos & $<$ Tempe. < QIC \\
\hline \multirow{2}{*}{$P$} & \multirow{2}{*}{ Preço das ações (20 e 21) } & Maior poder explicativo $\left(\mathrm{R}^{2}\right)$ de BVEPS e NIPS & > Relevância > QIC \\
\hline & & Menor poder explicativo $\left(\mathrm{R}^{2}\right)$ de BVEPS e NIPS & $>$ Relevância > QIC \\
\hline \multirow{2}{*}{$N I / P$} & \multirow{2}{*}{ Lucro por ação (22 e 23) } & Maior poder explicativo $\left(\mathrm{R}^{2}\right)$ de RETURN & > Relevância > QIC \\
\hline & & Menor poder explicativo de RETURN & > Relevância > QIC \\
\hline
\end{tabular}

Nota. GR: Gerenciamento de Resultados. QIC: Qualidade da Informação Contábil. BVEPS: Valor Patrimonial da ação. NIPS: lucro por ação. NI: Lucro Líquido. CF: Fluxo de Caixa. < ou > indicam sinais de menor ou maior, respectivamente.

As análises conduzidas nessa subseção consideram a integralidade das conexões existentes no nível da firma e no nível de integrantes e se referem a segunda fase delineada na subseção 3.1 deste estudo.

\subsubsection{Gerenciamento de Resultados}

Apresentam-se a seguir os resultados dos estimadores dos modelos que buscam examinar o efeito do Board Interlocking sobre as três métricas ligadas ao Gerenciamento de Resultados. Devido ao fato de serem examinadas 4 variáveis de Board Interlocking, ter-se-ão 12 equações no constructo de Gerenciamento de Resultados do Portfolio Approach. Considerando que para exame das hipóteses de pesquisa as alterações dessas equações são específicas para a cada uma das quatro variáveis de Board Interlocking e dada limitação de espaço para mostrar todas as equações, a exposição das equações ocorreu uma só vez conforme mostrado a seguir. Desse modo a descrição das tabelas 
mostradas a seguir poderão ser esclarecidas com o uso do Quadro 2 onde são detalhadas as direções de interpretação das métricas do Portfolio Approach.

Direções para Interpretação das métricas por Portfolio Approach de Barth et al. (2008)

$N I_{i t}=\beta_{1 i}+\beta_{2} B I_{2 i t}+\beta_{3} T A M_{3 i t}+\beta_{4} G R O W_{4 i t}+\beta_{5} E I S S U E_{5 i t}+\beta_{6} L E V_{2 i t}+\beta_{7} D I S S U E_{7 i t}+\beta_{8} D T U R N_{8 i t}$ $+\beta_{9} C F_{9 i t}+\beta_{10} A U D_{10 i t}+\beta_{11} A G E_{11 i t}+\lambda_{t}+\delta_{i}+\varepsilon_{i t}($ Equação 1)

$\Delta N I_{i t} / \Delta C F_{i t}=\beta_{1 i}+\beta_{2} B I_{2 i t}+\beta_{3}$ TAM $M_{3 i t}+\beta_{4}$ GROW $W_{4 i t}+\beta_{5} E I S S U E_{5 i t}+\beta_{6} L E V_{2 i t}+\beta_{7} D I S S U E_{7 i t}+$

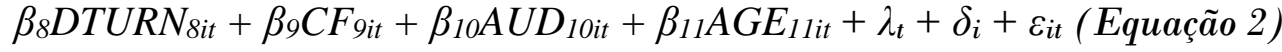

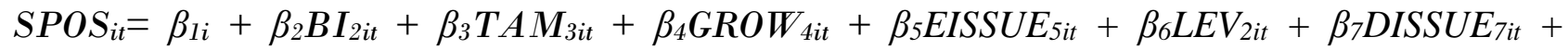
$\beta_{8} D T U R N_{8 i t}+\beta_{9} C F_{9 i t}+\beta_{10} A U D_{10 i t}+\beta_{11} A G E_{11 i t}+\lambda_{t}+\delta_{i}+\varepsilon_{i t}($ Equação 3)

Tabela 7 - Resultado das regressões múltiplas para as variáveis de Gerenciamento de Resultados do Portfolio Approach

\begin{tabular}{|c|c|c|c|}
\hline \multirow{2}{*}{ Variáveis independentes } & \multicolumn{3}{|c|}{ Variáveis dependentes } \\
\hline & Modelo $1\left(N I_{i t}\right)$ & Modelo $2\left(\triangle N I_{i t} / \triangle C F_{i t}\right)$ & Modelo $3\left(S P O S_{i t}\right)$ \\
\hline \multirow{2}{*}{$\underline{B \boldsymbol{I}_{i t}}$} & 0,0014260 & $-0,0012915$ & $-0,0048960$ \\
\hline & $(0,003914)$ & $(0,007972)$ & $(0,006460)$ \\
\hline \multirow{2}{*}{$T A M_{i t}$} & 0,0004320 & $0,0379486 * * *$ & $0,0223629 *$ \\
\hline & $(0,000759)$ & $(0,009502)$ & $(0,011493)$ \\
\hline \multirow{2}{*}{ CRESC $_{i t}$} & $-0,0000093$ & 0,0000462 & 0,0000814 \\
\hline & $(0,000065)$ & $(0,000041)$ & $(0,000095)$ \\
\hline \multirow{2}{*}{$E_{I S S U} E_{i t}$} & $0,0000159 * * *$ & 0,0000035 & $-0,0000047 * * *$ \\
\hline & $(0,000001)$ & $(0,000006)$ & $(0,000001)$ \\
\hline \multirow{2}{*}{$L E V_{i t}$} & $-0,0003185 * * *$ & 0,0000042 & $-0,0002411 *$ \\
\hline & $(0,000078)$ & $(0,000096)$ & $(0,000132)$ \\
\hline \multirow{2}{*}{$D_{I S S U} E_{i t}$} & $-0,0000513$ & 0,0000179 & $-0,0000707$ \\
\hline & $(0,000051)$ & $(0,000056)$ & $(0,000128)$ \\
\hline \multirow{2}{*}{$T U R N_{i t}$} & $0,0061950 *$ & $-0,0359515^{* *}$ & $0,0487935 * *$ \\
\hline & $(0,003183)$ & $(0,014827)$ & $(0,020018)$ \\
\hline \multirow{2}{*}{$C F_{i t}$} & $0,0692734 * * *$ & $0,9442680 * * *$ & $0,1616420 * * *$ \\
\hline & $(0,017224)$ & $(0,059494)$ & $(0,038459)$ \\
\hline \multirow{2}{*}{$A U D_{i}$} & $-0,0005306$ & $-0,0003450$ & 0,0032314 \\
\hline & $(0,002539)$ & $(0,002869)$ & $(0,003182)$ \\
\hline \multirow{2}{*}{$A G E_{i t}$} & $-0,0003357 * *$ & $-0,0025635 * *$ & $-0,0114954 * *$ \\
\hline & $(0,000134)$ & $(0,001216)$ & $(0,001616)$ \\
\hline \multirow{2}{*}{ Intercepto } & $-0,0143513$ & $-0,5369990 * * *$ & - \\
\hline & $(0,011462)$ & $(0,135115)$ & - \\
\hline Controle setorial $\left(\delta_{i}\right)$ & Sim & Sim & Sim \\
\hline Ano $\left(\lambda_{t}\right)$ & Sim & Sim & Sim \\
\hline$R^{2} a j u s t a d o$ & $2,50 \%$ & $40,86 \%$ & - \\
\hline
\end{tabular}

Nota. $*$, ** e $\mathrm{e}^{* * *}$, significativo ao nível de $10 \%, 5 \%$ e $1 \%$, respectivamente. A computação dos estimadores do modelo ocorreu considerando estimadores robustos a heterocedasticidade e autocorrelação serial. Controle Setorial: inclusão de dummies setoriais. Ano: Inclusão de dummies anuais. Erros-padrão entre parênteses.

Tendo em conta a formulação da hipótese de pesquisa, espera-se que o Board Interlocking deteriore a Qualidade da Informação Contábil. Isso significa que caso da empresa tenha-se envolvido em $B I$, a variabilidade de lucro $(\triangle N I)$ e a razão da variabilidade do lucro sobre a variabilidade dos fluxos de caixa ( $\triangle N I / \triangle C F$ ) será menor. Com isso, o sinal esperado para as variáveis $B I_{i t}$, DEGREE_LN $N_{i t}, B I S_{i t}$ e BISPER $i t$ é negativo. Para os Modelos cuja variável dependente seja SPOS 
(variável dicotômica que indica "1" para o reconhecimento de pequenos lucros - entre $0 \%$ e $1 \%$ - e "0" para o restante), espera-se o envolvimento da empresa em Board Interlocking aumentem as chances de reconhecimento de pequenos lucros. Logo, o sinal esperado para as variáveis de Board Interlocking é positivo.

Na Tabela 7 são apresentados os resultados para os modelos que envolvem a primeira variável de Board Interlocking.

Observa-se que o erro-padrão associado a todos os estimadores para $B I_{i t}$ Modelos 1, 2 e 3) é maior que o valor do próprio estimador. Isso significa que o valor de $t$ calculado está entre $-1,96 \mathrm{e}$ $+1,96$, não sendo possível rejeitar a hipótese nula de que o estimador para $B I_{i t}$ seja nulo. Os resultados evidenciam a ausência de influência significativa do Board Interlocking e métricas de Gerenciamento de Resultados. Assim, os resultados mostrados não sustentam a hipótese de que companhias cujos Conselhos de Administração, Diretorias e Conselhos Fiscais tenham-se conectado no período analisado tenham gerenciado resultados na direção de diminuir a variabilidade do lucro líquido, a variabilidade da razão ente lucro líquido e fluxos de caixa e aumentar a probabilidades do reconhecimento de pequenos lucros e, portanto, prejudicar a Qualidade da Informação Contábil reportada ao mercado de capitais.

Na Tabela 8 são apresentados os resultados para os modelos que envolvem a variável DEGREE_LN $N_{i t}$ de Board Interlocking.

Tabela 8 - Resultado das regressões múltiplas para as variáveis de Gerenciamento de Resultados do Portfolio Approach

\begin{tabular}{|c|c|c|c|}
\hline \multirow{2}{*}{$\begin{array}{c}\text { Variáveis } \\
\text { independentes }\end{array}$} & \multicolumn{3}{|c|}{ Variáveis dependentes } \\
\hline & Modelo $4\left(N I_{i t}\right)$ & Modelo $5\left(\Delta N I_{i t} / \Delta C F_{i t}\right)$ & Modelo $6\left(S P O S_{i t}\right)$ \\
\hline \multirow{2}{*}{$\underline{D E G R E E L N_{i t}}$} & $-0,0000700$ & 0,0005567 & $0,0012505 *$ \\
\hline & $(0,000240)$ & $(0,000714)$ & $(0,000737)$ \\
\hline \multirow{2}{*}{$T A M_{i t}$} & 0,0006035 & $\mathbf{0 , 0 3 7 7 4 8 0} * * *$ & $0,0218151 *$ \\
\hline & $(0,000787)$ & $(0,009564)$ & $(0,011323)$ \\
\hline \multirow{2}{*}{ CRESC $_{i t}$} & $-0,0000093$ & 0,0000486 & 0,0000896 \\
\hline & $(0,000065)$ & $(0,000038)$ & $(0,000094)$ \\
\hline \multirow{2}{*}{$E I S S U E_{i t}$} & $0,0000142 * * *$ & 0,0000034 & $-0,0000048 * * *$ \\
\hline & $(0,00000121)$ & $(0,000006)$ & $(0,000001)$ \\
\hline \multirow{2}{*}{$L E V_{i t}$} & $-0,0003179 * * *$ & 0,0000042 & $-0,0002407 *$ \\
\hline & $(0,000077)$ & $(0,000096)$ & $(0,000131)$ \\
\hline \multirow{2}{*}{$D I S S U E_{i t}$} & $-0,0000519$ & 0,0000147 & $-0,0000822$ \\
\hline & $(0,000050)$ & $(0,000052)$ & $(0,000127)$ \\
\hline \multirow{2}{*}{$T U R N_{i t}$} & $0,0062283 *$ & $-0,0358036 * *$ & $0,0489298 * *$ \\
\hline & $(0,003184)$ & $(0,014872)$ & $(0,020116)$ \\
\hline \multirow{2}{*}{$C F_{i t}$} & $0,0704063 * * *$ & $0,9438470 * * *$ & $0,1607160 * * *$ \\
\hline & $(0,0169968)$ & $(0,059353)$ & $(0,038747)$ \\
\hline \multirow{2}{*}{$A U D_{i}$} & $-0,0005038$ & $-0,0004337$ & 0,0030581 \\
\hline & $(0,002551)$ & $(0,002852)$ & $(0,003150)$ \\
\hline \multirow{2}{*}{ Idade } & $-0,0003371 * *$ & $-0,0025781 * *$ & $-0,0115189 * * *$ \\
\hline & $(0,000135)$ & $(0,001225)$ & $(0,001595)$ \\
\hline \multirow{2}{*}{ Intercepto } & 0,0151919 & $-0,5367480 * * *$ & - \\
\hline & $(0,011640)$ & $(0,135164)$ & - \\
\hline Controle Setorial $\left(\delta_{i}\right)$ & Sim & Sim & Sim \\
\hline $\operatorname{Ano}\left(\lambda_{t}\right)$ & Sim & Sim & Sim \\
\hline$R^{2}$ ajustado & $3,03 \%$ & $40,89 \%$ & - \\
\hline
\end{tabular}

Nota. *, ** e e $^{* *}$, significativo ao nível de $10 \%, 5 \%$ e $1 \%$, respectivamente. A computação dos estimadores do modelo ocorreu considerando estimadores robustos a heterocedasticidade e autocorrelação serial. Controle Setorial: inclusão de dummies setoriais. Ano: Inclusão de dummies anuais. Erros-padrão entre parênteses. 
O resultado do erro padrão associado aos estimadores para DEGREE_LN $N_{i t}$ para os Modelos 4 e 5 são maiores que o valor do próprio estimador. Isso significa que o valor de $t$ calculado está entre $-1,96$ e $+1,96$, não sendo possível rejeitar a hipótese nula de que o estimador para $D E G R E E \_L N_{i t}$ seja igual a zero. No entanto, o Modelo 3 evidencia que a razão observada entre o estimador de $D E G R E E \_L N_{i t}$ e o erro de estimação foi de 1,69674. Este valor $t$ calculado tem $p$-valor associado de 0,0945 e, portanto significativo ao nível de $10 \%$ e com sinal coerente com o esperado para a variável. Embora fraco, os resultados para este modelo sugerem que a variável de centralidade em grau exerce efeito em aumentar as chances de ocorrência de pequenos lucros, indicado que empresas com elevada frequência de conexões associada a elevado número de integrantes que compõe essas conexões tendem a aumentar as chances de manipular resultados na direção de divulgar pequenos lucros. Ressalte-se que para rejeição da hipótese nula o p-valor mínimo para é de 5\%. Logo, embora se reconheça a existência de efeitos sobre a variável dependente utilizada representar o reconhecimento de pequenos, os resultados alcançados para o Modelo 3 também não sustentam a hipótese de influência negativa do Board Interlocking sobre a Qualidade da Informação Contábil.

$\mathrm{Na}$ Tabela 9 e 10 são apresentados os resultados para os modelos que envolvem a variáveis ligadas a sobrecarga de integrantes de Conselhos de Administração, Diretorias e Conselhos Fiscais.

Tabela 9 - Resultado das regressões múltiplas para as variáveis de Gerenciamento de Resultados considerando companhias com e sem Sobrecarga

\begin{tabular}{|c|c|c|c|}
\hline \multirow{2}{*}{ Variáveis independentes } & \multicolumn{3}{|c|}{ Variáveis dependentes } \\
\hline & Modelo $7\left(N I_{i t}\right)$ & Modelo $8\left(\Delta N I_{i t} / \Delta C F_{i t}\right)$ & Modelo $9\left(S P O S_{i t}\right)$ \\
\hline \multirow{2}{*}{$\underline{B I S_{i t}}$} & 0,0005436 & $-0,0055071$ & $-0,0017354$ \\
\hline & $(0,002915)$ & $(0,008319)$ & $(0,008268)$ \\
\hline \multirow{2}{*}{$T A M_{i t}$} & $-0,0000463$ & $0,0329236 * * *$ & 0,0169449 \\
\hline & $(0,000800)$ & $(0,009769)$ & $(0,011455)$ \\
\hline \multirow{2}{*}{ CRESC $_{i t}$} & $-0,0001301 * *$ & $0,0094814 * * *$ & 0,0028383 \\
\hline & $(0,000051)$ & $(0,003488)$ & $(0,002082)$ \\
\hline \multirow{2}{*}{$E I S S U E_{i t}$} & $0,0000158 * * *$ & 0,0000048 & $-0,0000052 * * *$ \\
\hline & $(0,0000009)$ & $(0,000006)$ & $(0,0000015)$ \\
\hline \multirow{2}{*}{$L E V_{i t}$} & $-0,0003635 * * *$ & 0,0000058 & $-0,0002537 *$ \\
\hline & $(0,0000683)$ & $(0,000098)$ & $(0,0001436)$ \\
\hline \multirow{2}{*}{$D I S S U E_{i t}$} & $-0,0000225$ & $0,0011674 * *$ & $0,0000917 * * *$ \\
\hline & $(0,0000412)$ & $(0,0006621)$ & $(0,00002402)$ \\
\hline \multirow{2}{*}{$T U R N_{i t}$} & $0,0071855 * *$ & $-0,0361047 * * *$ & $0,0829357 * * *$ \\
\hline & $(0,0031940)$ & $(0,0138061)$ & $(0,0165916)$ \\
\hline \multirow{2}{*}{$C F_{i t}$} & $0,0734937 * * *$ & $0,9585710 * * *$ & $0,1710310 * * *$ \\
\hline & $(0,0174861)$ & $(0,0567358)$ & $(0,0397095)$ \\
\hline \multirow{2}{*}{$A U D_{i}$} & 0,0012503 & 0,0003559 & 0,0013254 \\
\hline & 0,0025148 & 0,0028658 & 0,0030351 \\
\hline \multirow{2}{*}{ Idade } & $-0,0003371 * *$ & $-0,0009281$ & $-0,0104216 * * *$ \\
\hline & $(0,0001412)$ & $(0,0012569)$ & $(0,0016993)$ \\
\hline \multirow{2}{*}{ Intercepto } & $-0,0069656$ & $-0,5016610 * * * *$ & - \\
\hline & 0,0123420 & 0,1394890 & - \\
\hline Controle Setorial $\left(\delta_{i}\right)$ & Sim & Sim & Sim \\
\hline Ano $\left(\lambda_{t}\right)$ & Sim & Sim & Sim \\
\hline$R^{2}$ ajustado & $3,96 \%$ & $42,28 \%$ & - \\
\hline
\end{tabular}

Nota. *, ** e ***, significativo ao nível de 10\%, $5 \%$ e 1\%, respectivamente. A computação dos estimadores do modelo ocorreu considerando estimadores robustos a heterocedasticidade e autocorrelação serial. Controle Setorial: inclusão de dummies setoriais. Ano: Inclusão de dummies anuais. Erros-padrão entre parênteses. 

EMPRESAS BRASILEIRAS

Os resultados evidenciam não haver efeito da sobrecarga de Conselhos de Administração sobre métricas de Gerenciamento de Resultados. Dessa forma, os resultados mostrados para os modelos 7, 8 e 9 não sustentam a hipótese de que companhias com Conselhos de Administração sobrecarregados tenham gerenciado resultados na direção de diminuir a variabilidade do lucro líquido, a variabilidade da razão ente lucro líquido e fluxos de caixa e aumentar a probabilidades do reconhecimento de pequenos lucros e, portanto, prejudicar a Qualidade da Informação Contábil reportada ao mercado de capitais.

Tabela 10 - Resultado das regressões múltiplas para as variáveis de Gerenciamento de Resultados considerando companhias com e sem Sobrecarga

\begin{tabular}{|c|c|c|c|}
\hline \multirow{2}{*}{ Variáveis independentes } & \multicolumn{3}{|c|}{ Variáveis dependentes } \\
\hline & Modelo $10\left(N I_{i t}\right)$ & Modelo $11\left(\triangle N I_{i t} / \Delta C F_{i t}\right)$ & Modelo $12\left(\right.$ SPOS $\left._{i t}\right)$ \\
\hline \multirow{2}{*}{$\underline{B I S P E R_{i t}}$} & $-0,0006904$ & $-0,0007813$ & $-0,0005571$ \\
\hline & $(0,0018503)$ & 0,0025014 & 0,0017560 \\
\hline \multirow{2}{*}{$T A M_{i t}$} & $-0,0000333$ & $\mathbf{0 , 0 3 2 9 1 2 5 * * *}$ & 0,0169496 \\
\hline & $(0,0008042)$ & $(0,0097425)$ & $(0,011469)$ \\
\hline \multirow{2}{*}{$\operatorname{CRESC}_{i t}$} & $-0,0001296 * *$ & $0,0094948 * * *$ & 0,0028358 \\
\hline & $(0,0000512)$ & $(0,0034895)$ & $(0,002068)$ \\
\hline \multirow{2}{*}{ EISSUE $_{i t}$} & $0,0000157 * * *$ & 0,0000047 & $-0,0000053 * * *$ \\
\hline & $(0,0000010)$ & $(0,0000060)$ & $(0,0000015)$ \\
\hline \multirow{2}{*}{$L E V_{i t}$} & $-0,0003639 * * *$ & 0,0000062 & $-0,0002535 *$ \\
\hline & $(0,0000681)$ & 0,0000985 & $(0,0001437)$ \\
\hline \multirow{2}{*}{$D_{I S S U E}$} & $-0,0000227$ & 0,0011676* & 0,0000924 \\
\hline & $(0,0000409)$ & $(0,0006628)$ & $(0,000239)$ \\
\hline \multirow{2}{*}{$T U R N_{i t}$} & $0,0072050 * *$ & $-0,0359708 * *$ & $0,0828585 * * *$ \\
\hline & $(0,0031776)$ & $(0,0139454)$ & $(0,0165114)$ \\
\hline \multirow{2}{*}{$C F_{i t}$} & $0,0730765 * * *$ & $0,9577010 * * *$ & $0,1706430 * * *$ \\
\hline & $(0,0169222)$ & $(0,0564629)$ & $(0,0398765)$ \\
\hline \multirow{2}{*}{$A U D_{i}$} & 0,0011343 & 0,0002834 & 0,0012388 \\
\hline & $(0,002544)$ & $(0,002943)$ & $(0,003247)$ \\
\hline \multirow{2}{*}{ Idade } & $-0,0003398 * *$ & $-0,0009577$ & $-0,0104500 * * *$ \\
\hline & $(0,0001409)$ & $(0,001255)$ & $(0,0017297)$ \\
\hline \multirow{2}{*}{ Intercepto } & $-0,0068887$ & $-0,5016410 * * *$ & - \\
\hline & $(0,012313)$ & $(0,1393130)$ & - \\
\hline Controle Setorial & Sim & Não & Não \\
\hline Ano & Sim & Sim & Sim \\
\hline$R^{2}$ ajustado & $3,96 \%$ & $42,26 \%$ & - \\
\hline
\end{tabular}

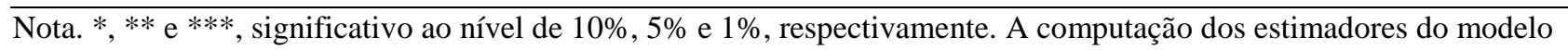
ocorreu considerando estimadores robustos a heterocedasticidade e autocorrelação serial. Controle Setorial: inclusão de dummies setoriais. Ano: Inclusão de dummies anuais. Erros-padrão entre parênteses.

Nota-se na Tabela 10 que os coeficientes de BISPER it para os Modelos 10,11 e 12 apresentaram erros-padrão associados aos estimadores que ultrapassaram o valor dos coeficientes impossibilitando a rejeição da hipótese nula de que o indicador é igual a zero. Assim, ao seguir a mesma direção dos resultados anteriormente apresentados, a Tabela 9 também mostrou ser insignificante a influência da sobrecarga sobre a Qualidade da Informação Contábil.

\subsubsection{Conservadorismo Contábil}

A segunda hipótese definida nessa pesquisa é de que o fenômeno Board Interlocking exerce influência negativa sobre a Qualidade da Informação Contábil diminuindo o Conservadorismo de empresas brasileiras. Nesta etapa, mostram-se o modelo econométrico utilizado para determinação 
do Conservadorismo Contábil e as Equações cujas estimações dos parâmetros irão intermediar o exame da Hipótese desenvolvida na seção 2. O Portfolio Approach proposto por Barth et al. (2008) não faz referência às medidas de Conservadorismo Contábil. Nesse estudo, a proxy para Conservadorismo será determinada por meio do modelo de Ball e Shivakumar (2005), que na sua origem tem a seguinte especificação:

$$
\Delta N I_{i t}=\beta_{0}+\beta_{1} D \Delta N I_{i t-1}+\beta_{2} D \Delta N I_{i t-1}+\beta_{3} D \Delta N I_{i t-1} * D \Delta N I_{i t-1}+\varepsilon_{i t}(\text { Equação 4) }
$$

Ganhos reconhecidos oportunamente representam um componente temporário do resultado porque podem estar associados a elementos incertos. Logo, há chances de sofrerem reversões em períodos subsequentes. Diante da possibilidade de reversão e para constatação dessa circunstância em um conjunto de empresas, o coeficiente angular $\beta_{3}$ deveria ser negativo $\left(\beta_{3}<0\right)$. Desse modo, a suposição de que perdas econômicas são reconhecidas mais rapidamente do que ganhos supõem que o coeficiente angular resultante da interação entre a variação no lucro líquido no período anterior $\left(\Delta N I_{i t-1}\right)$ e a dummy para reconhecimento de resultados negativos também em período anterior $\left(D \Delta N I_{i t-1}\right)$ seja negativo. Em suma, o Conservadorismo Contábil é observado nas empresas de determinada amostra quando do reconhecimento mais rápido de perdas e não de ganhos. Considerando o modelo apresentado na Equação 15 essas suposições indicam que para a observação do Conservadorismo Contábil é necessário respeitar as desigualdades $\beta_{3}<0$ e $\beta_{2}+\beta_{3}<0$ (Ball e Shivakumar, 2005).

Diferente das Equações apresentadas nas especificações dos Modelos da Hipótese relacionada ao Gerenciamento de Resultados, para a Hipótese ligada ao Conservadorismo Contábil não há uma métrica específica para se observá-lo. A observância do Conservadorismo depende do exame de coeficientes de Modelos de regressão propostos a fim de se identificar o efeito do Conservadorismo sobre outra variável. O exame empírico que se busca realizar é de o Board Interlocking torna o reporte contábil menos conservador e, portanto, o Board Interlocking exerceria efeito negativo sobre o Conservadorismo Contábil. Para que isso seja observado, propuseram-se das seguintes equações:

$$
\begin{aligned}
& \Delta N I_{i t}=\beta_{0}+\beta_{1} D \Delta N I_{i t-1}+\beta_{2} \Delta N I_{i t-1}+\beta_{3} \Delta N I_{i t-1} * D \Delta N I_{i t-1}+\beta_{4} D E G R E E_{-} L N * D \Delta N I_{i t-1}+ \\
& \beta_{5} D E G R E E \_L N * \Delta N I_{i t-1}+\beta_{6} D E G R E E_{-} L N * \Delta N I_{i t-1} * D \Delta N I_{i t-1}+\varepsilon_{i t}(\text { Equação } 5)
\end{aligned}
$$

$$
\begin{aligned}
& \triangle N I_{i t}=\beta_{0 i}+\beta_{1} D \Delta N I_{i t-1}+\beta_{2} \Delta N I_{i t-1}+\beta_{3} \Delta N I_{i t-1} * D \Delta N I_{i t-1}+\beta_{4} B I S P E R \_L N * D \Delta N I_{i t-1}+\beta_{5} B I S P E R \_L N \\
& * \Delta N I_{i t-1}+\beta_{6} B I S P E R \_L N * \Delta N I_{i t-1} * D \Delta N I_{i t-1}+\varepsilon_{i t}(\text { Equação } 6)
\end{aligned}
$$

Nas Equações 5 e 6 foram incluídas as variáveis relacionadas ao Board Interlocking. Para que seja identificada a influência negativa das variáveis do BI, as estimações dos parâmetros das Equações precisam satisfazer a desigualdade $\left(\beta_{2}+\beta_{3}\right)<\left(\beta_{2}+\beta_{3}+\beta_{5}+\beta_{6}\right)$. Metodologia semelhante foi adotada por Silva, Almendra, De Luca e Rebouças (2016).

Mostram-se na Tabela 11 os resultados das estimações dos Modelos 13, 14 e 15. No Modelo 13 apresentam-se as estimações da Equação 4 Conservadorismo Condicional conforme especificações de Ball e Shivakumar (2005). A presença desse modelo na descrição tem o objetivo de examinar a coerência dos resultados dos coeficientes em termos de observação sobre indícios de reconhecimento oportunos de perdas pelas empresas estudas. No Modelo 14 a variável de interesse refere-se ao Board Interlocking e envolve o indicador de centralidade em grau ponderada pelo valor do logaritmo da quantidade de integrantes. Espera-se que o Board Interlocking exerça efeito de diminuição do Conservadorismo Contábil e, portanto potencial em piorar a Qualidade da Informação Contábil. Logo, para o Modelo 2, faz-se necessário que se satisfaça a desigualdade dada pela relação $\left(\beta_{2}+\beta_{3}\right)<\left(\beta_{2}+\beta_{3}+\beta_{5}+\beta_{6}\right)$ para que seja observada diminuição no nível de conservadorismo contábil nas empresas analisadas. Na mesma direção, espera-se que à medida que se expanda a presença 
Conselheiros ocupantes de 3 ou mais posições simultaneamente, ocorra a diminuição do Conservadorismo Contábil. Assim, reflexos de influência da sobrecarga sobre a diminuição do Conservadorismo Contábil serão observados se a condição de desigualdade dada por $\left(\beta_{2}+\beta_{3}\right)<\left(\beta_{2}\right.$ $+\beta_{3}+\beta_{5}+\beta_{6}$ ) for atendida.

Tabela 11 - Resultado das regressões múltiplas para exame da influência do Board Interlocking sobre o Conservadorismo Contábil

\begin{tabular}{|c|c|c|c|}
\hline \multirow{2}{*}{ Variáveis independentes } & \multicolumn{3}{|c|}{ Variável dependente: $\Delta N I_{i t}$} \\
\hline & Modelo 13 & Modelo 14 & Modelo 15 \\
\hline \multirow{2}{*}{ (1) $D \Delta N I_{t-1}$} & $-0,0416423 * *$ & $-0,0278020^{*}$ & $-0,1365177 * * *$ \\
\hline & $(0,0182095)$ & $(0,0154040)$ & $(0,0400200)$ \\
\hline \multirow{2}{*}{ (2) $\Delta N I_{t-1}$} & $-0,1601234 * * *$ & $-0,5831990 * * *$ & $-0,3399305 * *$ \\
\hline & $(0,0522805)$ & $(0,1744425)$ & $(0,1075700)$ \\
\hline \multirow{2}{*}{ (3) $\Delta N I_{t-1} \times D \Delta N I_{t-1}$} & $0,0107111 * * *$ & $0,0037238 * *$ & 0,0007220 \\
\hline & $(0,0033986)$ & $(0,0016954)$ & $(0,0047039)$ \\
\hline \multirow{2}{*}{$D E G R E E \_L N x D \Delta N I_{t-1}$} & - & 1,5763830 & - \\
\hline & - & $(0,9635400)$ & - \\
\hline \multirow{2}{*}{ DEGREE_LNx $\triangle N I_{t-1}$} & - & 2,8340970 & - \\
\hline & - & $(1,9769120)$ & - \\
\hline \multirow{2}{*}{$D E G R E E \_L N x D \Delta N I_{t-1} x \Delta N I t-1$} & - & 0,0045500 & - \\
\hline & - & $(0,0094070)$ & - \\
\hline \multirow{2}{*}{$B I S P E R \times D \triangle N I_{t-1}$} & - & - & 0,0129131 \\
\hline & - & - & 0,0300563 \\
\hline \multirow{2}{*}{ BISPER $x \triangle N I_{t-1}$} & - & - & 0,0042626 \\
\hline & - & - & 0,0982371 \\
\hline \multirow{2}{*}{$B I S P E R \times D \triangle N I_{t-1} x \Delta N I t-1$} & - & - & 0,0007569 \\
\hline & - & - & 0,2208094 \\
\hline \multirow{2}{*}{ Intercepto } & $0,9609450 *$ & 1,7293000 & $(0,2523900)$ \\
\hline & $(0,5463200)$ & $(1,3908410)$ & $(0,1605100)$ \\
\hline $\mathrm{R}^{2}$ ajustado & $8,13 \%$ & $10,06 \%$ & $7,64 \%$ \\
\hline
\end{tabular}

Nota. *, ** e e $^{* *}$, significativo ao nível de $10 \%, 5 \%$ e $1 \%$, respectivamente. A computação dos estimadores do modelo ocorreu considerando estimadores robustos a heterocedasticidade e autocorrelação serial. Controle Setorial: inclusão de dummies setoriais. Ano: Inclusão de dummies anuais. Erros-padrão entre parênteses.

Observa-se que, à exceção do intercepto, no Modelo 13 os valores estimados para os coeficientes angulares são maiores que os respectivos erros-padrão associados às suas estimações, tornando-os significativos ao nível de $5 \%$ e $1 \%$. No entanto, os resultados evidenciam que o coeficiente de $\Delta N I_{t-1} \times D \Delta N I_{t-1}$ é positivo, contrariando a identidade $\beta_{3 i t}<0$. O resultado positivo encontrado sugere que não foi comprovada a existência de reconhecimento assimétrico de perdas em relação à obtenção de ganhos e, como consequência, esses resultados mostram que, em média, as companhias da amostra têm propensão a não apresentar comportamento conservador em suas práticas contábeis. Isto é, as estimações do Modelo 13 indicam que as corporações estariam mais propensas ao reconhecimento oportuno de ganhos econômicos, o que contraria a ideia do Conservadorismo Contábil proposto no Modelo de Ball e Shivakumar (2005) que versa sobre o reconhecimento oportuno de perdas.

No Modelo 14, vê-se que a soma dos coeficientes estimados incluindo as variáveis relacionadas ao Board Interlocking $\left(\beta_{2}, \beta_{3}, \beta_{5}\right.$ e $\left.\beta_{6}\right)$ é 2,259. Observa-se também que a soma de $\left(\beta_{2} \mathrm{e}\right.$ $\left.\beta_{3}\right)$ é $-0,579$. Tendo sido a desigualdade $\left(\beta_{2}+\beta_{3}\right)<\left(\beta_{2}+\beta_{3}+\beta_{5}+\beta_{6}\right)$ satisfeita é possível observar a influência do Board Interlocking sobre o Conservadorismo Contábil na direção de tornar possível a 
afirmação de que o $B I$ concorre para a diminuição do Conservadorismo Contábil em empresas brasileiras. No entanto, a Tabela 11 mostrou que os coeficientes estimados para as variáveis $D E G R E E_{-} L N_{i t}$ não são significativos em sua totalidade. Isso significa que, a rigor, não é possível rejeitar a hipótese nula de que seus valores são iguais à zero. Dessa maneira, ainda que a soma dos coeficientes evidenciem valor superior ao valor de referência de $-0,579$, os estimadores envolvidos na desigualdade não são expressivos. Desse modo, torna-se inconclusiva a afirmação de que Conselhos de Administração conectados exercem influência negativa sobre o Conservadorismo Contábil.

\subsubsection{Tempestividade da Informação Contábil}

A Tempestividade da Informação Contábil, identificada por $L N E G$, trata-se de uma variável dummy que assume o valor de " 1 " quando da ocorrência de prejuízo no tempo $t$ (escalado pelo valor do ativo também no tempo $t$ ) maior ou igual a $20 \%$ e "0" para o contrário, conforme Portfolio Approach proposto por Barth et al. (2008). Na Tabela 12 são apresentados os resultados considerando duas variáveis de Board Interlocking e duas variáveis de sobrecarga.

Tabela 12 - Resultado das regressões múltiplas para exame da influência do Board Interlocking sobre a Tempestividade da Informação Contábil

\begin{tabular}{|c|c|c|c|c|}
\hline \multirow{2}{*}{ Var. independentes } & \multicolumn{4}{|c|}{ Variável dependente: $L N E G_{i t}$} \\
\hline & Modelo 16 & Modelo 17 & Modelo 18 & Modelo 19 \\
\hline \multirow{2}{*}{$B I_{i t}$} & 0,0067220 & - & - & - \\
\hline & $(0,011269)$ & - & - & - \\
\hline \multirow{2}{*}{$D E G R E E \_L N_{i t}$} & - & $-0,0031001 * *$ & - & - \\
\hline & - & $(0,001448)$ & & - \\
\hline \multirow{2}{*}{$B I S_{i t}$} & - & - & $-0,0118035$ & - \\
\hline & - & - & $(0,009599)$ & - \\
\hline \multirow{2}{*}{$B_{I S P E R_{i t}}$} & - & - & - & $-0,0003737$ \\
\hline & - & - & - & $(0,003296)$ \\
\hline \multirow{2}{*}{$T A M_{i t}$} & $-0,0598686 * * *$ & $-0,0587763 * * *$ & $-0,0544217 * *$ & $-0,0545568 * *$ \\
\hline & $(0,020719)$ & $(0,020327)$ & $(0,021843)$ & $(0,021886)$ \\
\hline \multirow{2}{*}{ CRESC $_{i t}$} & 0,0000357 & 0,0000235 & $-0,0034101$ & $-0,0032491$ \\
\hline & $(0,000055)$ & $(0,000049)$ & $(0,006876)$ & $(0,006829)$ \\
\hline \multirow{2}{*}{$E I S S U E_{i t}$} & 0,0000017 & 0,0000020 & 0,0000019 & 0,0000021 \\
\hline & $(0,000003)$ & $(0,000003)$ & $(0,000003)$ & $(0,000003)$ \\
\hline \multirow{2}{*}{$L E V_{i t}$} & $-0,0003572$ & $-0,0003575$ & $-0,0003637$ & $-0,0003638$ \\
\hline & $(0,000351)$ & $(0,000349)$ & $(0,000380)$ & $(0,000380)$ \\
\hline \multirow{2}{*}{$D I S S U E_{i t}$} & $-0,0000684$ & $-0,0000514$ & $-0,0006893$ & $-0,0006885$ \\
\hline & $(0,000074)$ & $(0,000065)$ & $(0,000646)$ & $(0,000648)$ \\
\hline \multirow{2}{*}{$T U R N_{i t}$} & $-0,0228122$ & $-0,0236833$ & $-0,0237207$ & $-0,0226346$ \\
\hline & $(0,034119)$ & $(0,033756)$ & $(0,042506)$ & $(0,042612)$ \\
\hline \multirow{2}{*}{$C F_{i t}$} & $-0,0423887$ & $-0,0400453$ & 0,0282101 & 0,0264503 \\
\hline & $(0,072539)$ & $(0,072522)$ & $(0,075159)$ & $(0,075138)$ \\
\hline \multirow{2}{*}{$A U D_{i t}$} & 0,0053031 & 0,0058010 & 0,0045222 & 0,0049060 \\
\hline & $(0,005992)$ & $(0,005995)$ & $(0,005908)$ & $(0,006656)$ \\
\hline \multirow{2}{*}{ Idade $_{i t}$} & $0,0116639 * * *$ & $0,0117478 * * *$ & $\mathbf{0 , 0 1 1 0 3 3 3 * * * *}$ & $0,0111098 * * *$ \\
\hline & $(0,003354)$ & $(0,003336)$ & $(0,003503)$ & $(0,003552)$ \\
\hline
\end{tabular}

Intercepto

Nota. *, ** e ***, significativo ao nível de $10 \%, 5 \%$ e $1 \%$, respectivamente. A computação dos estimadores dos modelos ocorreu considerando erros-padrão robustos. Devido à estimação para Dados em painel por efeitos fixos, o parâmetro correspondente ao intercepto não é determinado (Fávero, 2015). Erros-padrão entre parênteses. Valores z tabelados (críticos) associados à significância de 5\%: $-1,96$ e +1,96.

Nota-se no Modelo 16 que o resultado do erro padrão do estimador de $B I_{i t}$ é maior que o valor do estimador, o que revela a impossibilidade de rejeição da hipótese nula. Com isso, mostra-se 
inconclusivo o efeito do envolvimento de Conselhos de Administração em Board Interlocking sobre o reconhecimento tempestivo de grandes prejuízos. No Modelo 2, observa-se que o resultado do erro padrão é menor que o resultado do coeficiente estimado para a variável $D E G R E E \_L N_{i t}$. Desse modo, é possível rejeitar a hipótese nula e, considerando o valor de z em 2,14 (0,0031001/0,001448), temse que o coeficiente é significativo ao nível de 5\%. Além disso, o sinal obtido está de acordo com o esperado. Observa-se que a variável Centralidade em Grau com ponderação da quantidade de integrantes que compõe as conexões da companhia foi capaz de capturar a influência sobre a Tempestividade. Esses resultados vão ao encontro da hipótese formulada e sugerem que elevações na centralidade diminuem a probabilidade de companhias em reconhecer grandes prejuízos. Portanto, correspondem a indícios de que a expansão de redes de conexões entre Conselhos de Administração tendem a diminuir a Qualidade da Informação Contábil no que tange a Tempestividade. Em relação aos Modelos 18 e 19, as variáveis de sobrecarga não apresentaram influência significativa sobre Tempestividade da Informação Contábil.

\subsubsection{Relevância da Informação Contábil}

De acordo com o Portfolio Approach a Relevância da Informação Contábil é examinada por dois Modelos cujas variáveis dependentes são preço $\left(\boldsymbol{P}_{i t}\right)$ e lucro por ação dividido pelo preço da ação no início de cada ano $\left(\boldsymbol{N I} / \boldsymbol{P}_{i t}\right)$. Deve-se ressaltar também que para essa dimensão de Qualidade da Informação Contábil, os modelos propostos não consideram variáveis de controle diferente dos demais já apresentados em seções anteriores. Para que fosse observada essa influência, a amostra de pesquisa foi dividida. Essa divisão ocorreu em duas fases. Na primeira fase (Tabela 13), a amostra de pesquisa foi subdivida em tercis. No primeiro tercil constam as empresas com menor valor calculado para a centralidade em grau associada à quantidade de integrantes da rede e no terceiro as companhias com o maior valor. Na segunda fase (Tabela 14) esse mesmo procedimento de separação em tercis foi aplicado para subdividir a amostra em termos sobrecarga. Utilizando-se a variável BISPER foram consideradas no primeiro tercil as companhias com o menor valor calculado para esse percentual e no terceiro as empresas com maior valor. Na Tabela 13, apresentam-se os resultados para os Modelos 20 e 21.

Tabela 13 - Resultado das regressões múltiplas para exame da influência do Board Interlocking (centralidade em grau) sobre a Relevância da Informação Contábil

\begin{tabular}{|c|c|c|c|c|}
\hline \multirow{2}{*}{$\begin{array}{c}\text { Variáveis } \\
\text { Independentes }\end{array}$} & \multicolumn{2}{|c|}{ Modelo 20} & \multicolumn{2}{|c|}{ Modelo 21} \\
\hline & $\begin{array}{c}\text { Regressão do } 1^{\circ} \\
\text { Quartil }\end{array}$ & $\begin{array}{c}\text { Regressão do } 3^{\circ} \\
\text { Quartil }\end{array}$ & $\begin{array}{c}\text { Regressão do } 1^{\circ} \\
\text { Quartil }\end{array}$ & $\begin{array}{c}\text { Regressão do } 3^{\circ} \\
\text { Quartil }\end{array}$ \\
\hline$B V E P S_{i t}$ & $\begin{array}{c}0,32109 * * * \\
0,0636\end{array}$ & $\begin{array}{c}0,25968 * * * \\
0,0536\end{array}$ & & \\
\hline$N I P S_{i t}$ & $\begin{array}{c}0,27583 * * * \\
0,0992\end{array}$ & $\begin{array}{c}0,65113 * * * \\
0,2443\end{array}$ & & \\
\hline$R_{E T U R N_{i t}}$ & & & $\begin{array}{c}0,35425^{* *} \\
0,1622 \\
\end{array}$ & $\begin{array}{c}0,21847 * * \\
0,0992 \\
\end{array}$ \\
\hline Intercepto & $\begin{array}{c}13,0294 * * * \\
1,29213\end{array}$ & $\begin{array}{c}11,791 * * * \\
1,11641 \\
\end{array}$ & $\begin{array}{c}-0,03995 \\
0,0358 \\
\end{array}$ & $\begin{array}{c}-0,00574 \\
0,0376 \\
\end{array}$ \\
\hline $\begin{array}{c}R^{2} \\
R^{2}-\text { Ajustado }\end{array}$ & $\begin{array}{l}18,97 \% \\
18,45 \%\end{array}$ & $\begin{array}{l}16,49 \% \\
15,99 \%\end{array}$ & $\begin{array}{c}0,07150 \\
6,89 \%\end{array}$ & $\begin{array}{c}0,01704 \\
1,39 \%\end{array}$ \\
\hline
\end{tabular}

Nota. *, ** e ***, significativo ao nível de $10 \%, 5 \%$ e $1 \%$, respectivamente.

Analisando-se o Modelo 20, a Tabela 13 evidencia que no primeiro tercil as variáveis lucro

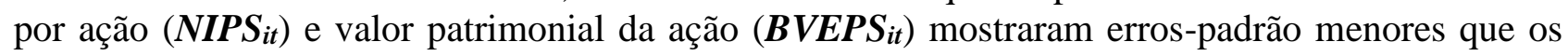
valores dos estimadores $(0,32109$ e 0,27583$)$ revelando elevados resultados para os valores $t$ calculados. Com isso, todos os estimadores mostraram-se significativos ao nível de $1 \%$ e, conjuntamente, produziram Coeficiente de Determinação ajustado $\left(R^{2}-\right.$ Ajustado $)$ de $18,45 \%$. No terceiro tercil, os estimadores para as variáveis $N I P S_{i t}$ e $B V E P S_{i t}$ também se mostraram significativas 
ao nível de $1 \%(0,25968$ e 0,65113$)$, mas produzindo $R^{2}$-ajustado menor com $15,99 \%$ de poder explicativo das variáveis contábeis, o que mostra que nas empresas em que há mais frequências de laços entre Conselheiros, o poder explicativo das variáveis contábeis sobre o preço da ação é menor.

Na Tabela 14 apresentam-se os resultados dos parâmetros da regressão linear dos Modelos 22 e 23 considerando a divisão da amostra pelo critério da variável BISPER.

Tabela 14 - Resultado das regressões múltiplas para exame da influência da sobrecarga Board sobre a Relevância da Informação Contábil

\begin{tabular}{|c|c|c|c|c|}
\hline \multirow{2}{*}{$\begin{array}{c}\text { Variáveis } \\
\text { Independentes }\end{array}$} & \multicolumn{2}{|c|}{ Modelo 22} & \multicolumn{2}{|c|}{ Modelo 23} \\
\hline & $\begin{array}{c}\text { Regressão do } 1^{\circ} \\
\text { Quartil }\end{array}$ & $\begin{array}{c}\text { Regressão do } 3^{\circ} \\
\text { Quartil }\end{array}$ & $\begin{array}{c}\text { Regressão do } 1^{\circ} \\
\text { Quartil }\end{array}$ & $\begin{array}{c}\text { Regressão do } 3^{\circ} \\
\text { Quartil }\end{array}$ \\
\hline \multirow{2}{*}{$B V E P S_{i t}$} & $0,29691 * * *$ & 0,14303 *** & & \\
\hline & 0,0532 & 0,0502 & & \\
\hline \multirow{2}{*}{$N I P S_{i t}$} & $0,22540 * * *$ & 0,03731 & & \\
\hline & 0,0721 & 0,0658 & & \\
\hline \multirow{2}{*}{$R_{E T U R N_{i t}}$} & & & $0,29086 * * *$ & $0,39258 * *$ \\
\hline & & & 0,1050 & 0,1926 \\
\hline \multirow{2}{*}{ Intercepto } & $12,5136 * * *$ & $12,8198 * * *$ & 0,01801 & $-0,08658 *$ \\
\hline & 1,2492 & 1,1953 & 0,0198 & 0,0518 \\
\hline Teste F & $31,8438 * * *$ & $11,2126^{* * *}$ & $7,68033 * * *$ & $4,15464 * * *$ \\
\hline$R^{2}$ & $16,99 \%$ & $6,74 \%$ & $11,48 \%$ & $3,46 \%$ \\
\hline$R^{2}-$ Ajustado & $16,44 \%$ & $6,14 \%$ & $11,15 \%$ & $3,10 \%$ \\
\hline
\end{tabular}

Nota. $* * *$ e $* * *$, significativo ao nível de $10 \%, 5 \%$ e $1 \%$, respectivamente.

Examinando-se a regressão do primeiro tercil no Modelo 1, nota-se que os valores dos errospadrão calculados são maiores que os estimadores das variáveis $N I P S_{i t}$ e $B V E P S_{i t}$, o que confere significância estatística ao nível de $1 \%$ para ambos os parâmetros. Essa regressão produziu Coeficiente de Determinação ajustado $\left(R^{2}\right.$-ajustado $)$ de $16,99 \%$ de poder explicativo das variáveis contábeis sobre o preço das companhias que compõe o tercil de empresas com menores percentuais de Conselheiros comprometidos com 3 ou mais empresas simultaneamente. No terceiro tercil, percebe-se que a variável $N I P S_{i t}$ deixa de ser significativa $(0,03731)$ e a regressão perde poder explicativo com queda do $R^{2}$ ajustado para $6,14 \%$, o que fortalece os indícios de perda de Relevância da Informação Contábil entre empresas cujos membros do Conselho de Administração tenham-se envolvidos em sobrecarga.

No Modelo 22, ao se considerar a regressão feita para o primeiro tercil, constata-se que o estimador para a variável $R E T U R N_{i t}$ se mostrou significante ao nível de 1\% (0,29086). Essa regressão gerou $\mathrm{R}^{2}$ ajustado de $11,15 \%$. Para as corporações que estão no terceiro tercil, embora o estimador se mantenha significativo ao nível de $5 \%(0,39258)$, observa-se queda no $\mathrm{R}^{2}$ ajustado para $3,10 \%$. A semelhança desses resultados aos demais observados conferem mais evidências de que a sobrecarga pode ser uma variável de influência sobre a Relevância da Informação Contábil.

Os resultados nessa subseção evidenciaram que empresas com maior centralidade em grau ponderada pela quantidade de integrantes e empresas com mais envolvimento em sobrecarga de seus conselheiros exibiram menor poder explicativo tanto no Modelo de Preços $\left(P_{i t}\right)$ quando no modelo de Retorno $\left(R E T U R N_{i t}\right)$. Assim, a análise de dados resultante desses modelos confirmou que o fenômeno Board Interlocking exerce influência negativa sobre a Qualidade da Informação Contábil diminuindo a Relevância da Informação Contábil de empresas brasileiras. Por outro lado, ainda que os resultados mostrados na Tabela 13 e 14 permitam essa afirmação, a abordagem utilizada por Barth et al. (2008) não utiliza controles específicos para examinar a Relevância da Informação Contábil. Por isso, essa circunstância deve ser reconhecida como uma limitação tendo em vista que a possibilidade de resultados diferentes caso um conjunto de variáveis de controle, de setores econômicos e variáveis de tempo fossem incluídas. 


\section{CONCLUSÕES}

Nas últimas duas décadas, estudos internacionais revelaram a dimensão interdisciplinar do fenômeno board interlocking e mostraram sua capacidade de polarização. Sob o ponto de vista empírico, este estudo realçou o caráter prejudicial do board interlocking sobre a informatividade da contabilidade para usuários externos. Isto porque investigou e desvendou a efetividade de atuação de Conselhos de Administração interconectados com outras empresas sobre a Qualidade da Informação Contábil conduzida a agentes externos a empresa, notadamente investidores de minoritários, analistas de mercado, investidores institucionais e reguladores. No que concerne à Regulação do Mercado de Capitais realizada pela Comissão de Valores Mobiliários, sobretudo em relação às regras para composição de Conselhos de Administração, este estudo representa uma consistente contribuição empírica ao mostrar, na forma de censo, a descrição do Board Interlocking no nível de integrantes e companhias no Brasil.

Por meio de diferentes abordagens descritivas e econométricas, a pesquisa contribui para a observação do exercício da competência do Conselho de Administração na redução da assimetria informacional da informação divulgada a investidores, órgãos reguladores e demais usuários do conteúdo informacional da contabilidade. O estudo ajudou a compreender os reflexos da adoção de mecanismos de funcionamento do Conselho de Administração e a delimitação da distribuição de responsabilidade e autoridade na condução de decisões de investimento e de financiamento. Em específico, a exposição genérica das frequências de ligações existentes no nível de empresas e no nível de integrantes permitiu observar diminuto número de pessoas atuantes em quantidade relativamente alta de empresas, sugerindo que a condição tendente a se perpetuar no comando das organizações brasileiras é a formação de uma elite restrita e invariante de empresários e profissionais.

À luz da separação da propriedade e controle essa constatação conduz a duas considerações. A primeira é a severa concentração de pessoas na ocupação de posições simultâneas nos Conselhos de Administração indicando a não aplicabilidade de divisão das Decisões de Gestão e Decisões de Controle em empresas brasileiras. Esta constatação contraria a lógica da Teoria de Separação de Propriedade e Controle, pois remete os Conselhos de Administração às Decisões de Gestão e Controle combinada com a concentração de múltiplas ocupações em Diretorias Executivas. Assim, corre-se o risco de comprometer negativamente a capacidade de Conselhos exercer seu importante papel de contenção de problemas de agência. A elevada concentração de ocupações simultâneas pode ter colocado os Conselhos de Administração do Brasil em armadilhas no que se refere a sua configuração estar propensa a potencializar conflitos de interesse em detrimento de contê-los.

A segunda consideração refere-se ao fato de que Fama e Jensen (1983) defendem como salutar a presença de outsiders em Conselhos de Administração, os quais exerceriam papel de especialistas em supervisão de executivos. Os dados empíricos mostram que integrantes outsiders estão conectados a outras empresas. Essas conexões alcançam uma frequência suficientemente elevada e reduz a capacidade desses integrantes exercerem o ofício de diligenciar sobre as Decisões de Controle. Com isso, torna-se iminente a transformação do ofício de Conselheiro em uma função decorativa ou de fins burocráticos e distante da supervisão diligente que restringe e que reprova o que pode está em desacordo com o interesse do acionista, investidor e demais stakeholders interessados do desempenho subjacente da companhia.

Em relação às Hipóteses de Pesquisa, observou-se: (1) os resultados não permitiram afirmar Brasil Conselhos de Administração conectados são capazes de propagar práticas que diminuam ou aumentem a Qualidade da Informação Contábil, tornando a atuação conectada desse Órgão de Administração indiferente à incidência de manipulação de lucros; (2) que empresas brasileiras em geral não são conservadoras no reconhecimento de perdas e há indícios de que companhias envolvidas em Board Interlocking e sobrecarga tendem a priorizar o reconhecimento de ganhos em detrimentos das perdas. No entanto, a ausência de robustez notada nessa relação não permitiu 
confirmar esta hipótese; (3) o fenômeno Board Interlocking não exerce influência negativa sobre a Qualidade da Informação Contábil diminuindo a Tempestividade da Informação Contábil;

Quanto ao fenômeno Board Interlocking exercer influência negativa sobre a Qualidade da Informação Contábil diminuindo a Relevância da Informação Contábil, observou-se que em empresas com menor nível de centralidade e menor sobrecarga de seus Boards há maior liquidez das ações e maior visibilidade institucional. Por sua vez, a visibilidade mantida por essas corporações tende a impor maior disciplina na elaboração de demonstrações contábeis, o que por sua vez reflete em informações com maior credibilidade.

Como limitações do estudo deve-se mencionar que parte expressiva das variáveis de pesquisa desse estudo relacionadas mensuração do Board Interlocking decorrem de observações diretas das conexões existentes entre empresas e integrantes de companhias brasileiras de capital aberto. Isso significa que em parte relevante do estudo não foram utilizadas proxies para examinar as conexões. Por outro lado, embora todas as métricas de Qualidade da Informação Contábil sejam representações quantitativas que seguem definições rígidas, estas podem não capturar o significado da intervenção proposital em Demonstrações Contábeis brasileiras, constituindo-se em barreira para a materialização da observação do Gerenciamento de Resultados, Conservadorismo Contábil, Tempestividade e Relevância da Informação Contábil.

\section{REFERÊNCIAS}

Adams, R. B., Hermalin, B. E., \& Weisbach, M. S. (2010). The role of boards of directors in corporate governance: A conceptual framework and survey. Journal of economic literature, 48(1), 58-107.

Ahmed, K., Hossain, M., \& Adams, M. B. (2006). The effects of board composition and board size on the informativeness of annual accounting earnings. Corporate governance: an international review, 14(5), 418-431.

Alves, S. M. G. (2011). The effect of the board structure on earnings management: evidence from Portugal. Journal of Financial Reporting and Accounting, 9(2), 141-160.

Baccouche, S., \& Omri, A. (2014). Multiple directorships of board members and earnings management: An empirical evidence from french listed companies. Journal of Economic and Financial Modelling, 2(1), 13-23.

Barth, M. E., Landsman, W. R., \& Lang, M. H. (2008). International accounting standards and accounting quality. Journal of accounting research, 46(3), 467-498.

Beasley, M. S. (1996). An Empirical analysis of the relation between the board of director composition and financial statement fraud. Accounting review, 71(4), 443-465.

Beekes, W., Pope, P., \& Young, S. (2004). The link between earnings timeliness, earnings conservatism and board composition: evidence from the UK. Corporate Governance: An International Review, 12(1), 47-59.

Bizjak, J., Lemmon, M., \& Whitby, R. (2009). Option backdating and board interlocks. The Review of Financial Studies, 22(11), 4821-4847.

Cai, Y., \& Sevilir, M. (2012). Board connections and M\&A transactions. Journal of Financial Economics, 103(2), 327-349.

Chiu, P. C., Teoh, S. H., \& Tian, F. (2012). Board interlocks and earnings management contagion. The Accounting Review, 88(3), 915-944.

Cooper, E., \& Uzun, H. (2012). Directors with a full plate: the impact of busy directors on bank risk. Managerial Finance, 38(6), 571-586.

Dimitropoulos, P. E., \& Asteriou, D. (2010). The Effect of board composition on the informativeness and quality of annual earnings: Empirical evidence from Greece. Research in International Business and Finance, 24(2), 190-205.

Fama, E. F., \& Jensen, M. C. (1983). Separation of ownership and control. The journal of law and Economics, 26(2), 301-325.

Fich, E. E. \& White, L. (2001). Why do CEOs reciprocally sit on each other's boards? New York University Center for Law and Business Working Paper \#CLB- 01-002. 
Fich, E., \& White, L. J. (2003). CEO Compensation and turnover: The effects of mutually interlocked boards. Wake Forest L. Rev., 38, 935.

Firth, M., Fung, P. M., \& Rui, O. M. (2007). Ownership, two-tier board structure, and the informativeness of earnings-Evidence from China. Journal of accounting and public policy, 26(4), 463-496.

Hermalin, B. E., \& Weisbach, M. S. (1991). The effects of board composition and direct incentives on firm performance. Financial Management, 20(4), 101-112.

Holtz, L., \& Sarlo Neto, A. (2014). Efeitos das Características do Conselho de Administração sobre a Qualidade da Informação Contábil no Brasil. Revista Contabilidade \& Finanças, 25(66), 255-266.

Felix, R. (2016). Examining the spread of high quality reporting through the corporate network. Advances in Accounting, 32(March), 31-41.

Fich, E. M., \& Shivdasani, A. (2006). Are busy boards effective monitors? The Journal of Finance, 61(2), 689-724.

Fracassi, C., \& Tate, G. (2012). External networking and internal firm governance. The Journal of Finance, 67(1), 153-194.

Hashim, H. A., \& Rahman, M. S. A. (2011). Multiple board appointments: are directors effective? International Journal of Business and Social Science, 2(17), 137-148.

Ishii, J., \& Xuan, Y. (2014). Acquirer-target social ties and merger outcomes. Journal of Financial Economics, 112(3), 344-363.

Jiraporn, P., Davidson III, W. N., DaDalt, P., \& Ning, Y. (2009). Too busy to show up? An analysis of directors' absences. The Quarterly Review of Economics and Finance, 49(3), 1159-1171.

Klein, A. (2002). Audit committee, board of director characteristics, and earnings management. Journal of accounting and economics, 33(3), 375-400.

Larcker, D. F., Richardson, S. A., Seary, A., \& Tuna, A. (2005). Back door links between directors and executive compensation. Available at SSRN 671063.

Loderer, C., \& Peyer, U. (2002). Board overlap, seat accumulation and share prices. European Financial Management, 8(2), 165-192.

Macavoy, P., Cantor, S., \& Peck, S. (1983). ALI proposals for increase control of the corporation by the board of directors - an economic analysis. In Statement of the Business Roundtable on the

American Law Institute's. Proposed Principles of Corporate Governance and Structure: Restatement and Recommendations.

Markarian, G., \& Parbonetti, A. (2009). Financial Interlocks and Earnings Management: Evidence from Italy. Available at SSRN 1396299.

Mindzak, J. (2013). Interlocked Boards of Directors, Voluntary Disclosures and Earnings Quality. Voluntary Disclosures and Earnings Quality, (February).

Mendes-da-Silva, W. (2011). Small worlds and board interlocking in Brazil: a longitudinal study of corporate networks, 1997-2007. Brazilian Finance Review, 4(4), 521-548.

Peasnell, K. V., Pope, P. F., \& Young, S. (2005). Board monitoring and earnings management: Do outside directors influence abnormal accruals? Journal of Business Finance \& Accounting, 32(7-8), 13111346.

Tham, Y. H., Nigar, S., \& Harjinder S. Multiple Directorships and Earnings Management. Disponível em http://www.afaans.org/openconf/2016/modules/request.php?module=oc program\&action=view.php\&id $=308 \&$ file $=1 / 308$.pdf

Santos, R. L., \& Silveira, A. M. (2007). Board Interlocking no Brasil: a participação de conselheiros em múltiplas companhias e seu efeito sobre o valor das empresas. Revista Brasileira de Finanças, 5(2).

Sarkar, J., Sarkar, S., \& Sen, K. (2008). Board of directors and opportunistic earnings management: Evidence from India. Journal of Accounting, Auditing \& Finance, 23(4), 517-551.

Shu, P. G., Yeh, Y. H., Chiu, S. B., \& Yang, Y. W. (2015). Board external connectedness and earnings management. Asia Pacific Management Review, 20(4), 265-274.

Vafeas, N. (2000). Board structure and the informativeness of earnings. Journal of Accounting and Public Policy, 19(2), 139-160.

Watts, R. L. (2003). Conservatism in accounting part I: Explanations and implications. Accounting Horizons, 17(3), 207-221. 